\title{
Diferenciais de Utilização do Cuidado de Saúde no Sistema Suplementar Brasileiro ${ }^{\star}$
}

\author{
- Monica Viegas ANDRAdE*
}

- ANa Carolina Maia **

\begin{abstract}
RESUMO
Este artigo investiga os diferenciais de utilização de serviços no sistema de saúde brasileiro a partir de uma análise contrafactual utilizando os dados da Pesquisa Nacional de Amostra Domiciliar de 1998 e 2003. Duas variáveis de utilização do cuidado médico foram selecionadas: consultas médicas e dias de internação. Os resultados sugerem a presença de sobreutilização para os dois tipos de cuidado, mas a magnitude desse diferencial é mais elevada para consultas do que para internações: para consultas, verificamos que os indivíduos que têm plano de saúde utilizam, em média, $25 \%$ a mais do que utilizariam se estivessem no sistema de saúde público e, para internações, esse diferencial está no intervalo de 8 a 15\%. Para contornar $a$ endogeneidade entre as decisões de ter plano de saúde e de utilização propomos três procedimentos. Os resultados são bastante robustos e estão em consonância com a evidência empírica internacional.
\end{abstract}

\section{PalavRAS-CHAVE}

risco moral, sistemas de saúde, demanda por serviços de saúde

\begin{abstract}
This paper investigates the existence of differentials of healthcare utilization between private and non private insured individuals using a counter-factual analysis. We estimate healthcare utilization for 1998 and 2003. Two variables of healthcare utilization have been selected: medical visits and the number of inpatient days. The main findings suggest a positive differential of utilization for private insured individuals. The magnitude of these differentials varies across types of medical care. Considering medical visits we found that each individual in the private sector uses $25 \%$ more services than if they only have access to healthcare services through public sector and for inpatient days this percentage is lower, around $10 \%$. We use three different procedures to deal with the endogeneity of private insurance decision. Our findings are very robust and in accordance with international empirical evidence.
\end{abstract}

\section{KEYWORDS}

moral hazard, health system, demand for health services

\section{JEL CLASSIFICATION}

D82, 111,118

\footnotetext{
* Agradecemos a Flávia Chein pela disponibilidade e pelos comentários sempre muito apropriados e relevantes.

* CEDEPLAR/FACE/UFMG. Endereço para contato: Av. Antônio Carlos, 6627 - Belo Horizonte - MG. E-mail: mviegas@cedeplar.ufmg.br.

** CEDEPLAR/FACE/UFMG. Bolsista do Conselho Nacional de Desenvolvimento Científico e Tecnológico - CNPq - Brasil. Endereço para contato: Av. Antônio Carlos, 6627 - Belo Horizonte - MG. E-mail: anacmaia@cedeplar.ufmg.br.

(Recebido em julho de 2007. Aceito para publicação em maio de 2008).
} 


\section{$1 \quad$ INTRODUÇÃO}

O sistema de saúde brasileiro é um sistema misto, com atuação dos setores público e privado no provimento e financiamento dos bens e serviços de saúde. O setor de saúde suplementar, caracterizado pelo financiamento privado, representa uma importante e significativa parcela do mercado de assistência médica no Brasil. Segundo dados da PNAD (Pesquisa Nacional por Amostra Domiciliar) para 2003, cerca de $25 \%$ da população possui algum tipo de plano ou seguro de saúde.

Diversos estudos têm analisado o comportamento dos indivíduos quanto à utilização dos serviços de saúde diante de diferentes formas de financiamento dos mesmos (NEWHOUSE, 1993; MANNING et al., 1987). Em geral, observa-se que quanto maior a cobertura do plano ou seguro de saúde, maior é o incentivo para os indivíduos escolherem mais cuidado, resultando, dessa forma, em um problema de risco moral. A introdução de mecanismos que minimizem as distorções no uso dos serviços resulta em ganhos de bem-estar para a sociedade, daí a importância de se conhecer a magnitude desses efeitos.

Ainda são poucos os trabalhos que investigam as inter-relações entre os setores de saúde público e privado no Brasil, bem como a atuação da assistência suplementar no mercado de bens e serviços de saúde. O objetivo deste trabalho é estimar o diferencial de utilização dos serviços de saúde no sistema suplementar vis-à-vis o sistema público de saúde. Esse diferencial pode ser interpretado como uma medida de risco moral conforme definido na teoria econômica, se supusermos que os custos envolvidos na utilização do sistema público correspondem aos custos monetários que os indivíduos enfrentariam na ausência de um sistema de seguro. Por outro lado, essa diferença pode refletir também as dificuldades de acesso ao serviço público se supusermos que o padrão ótimo de utilização é o observado no setor privado. Provavelmente, a diferença estimada deve-se tanto a um problema de risco moral quanto a diferenças no acesso entre os dois setores. ${ }^{1}$ A literatura empírica brasileira já aponta evidências de desigualdade social no acesso aos serviços de saúde (NORONHA; ANDRADE, 2001). Neste trabalho, procuramos estimar o diferencial de utilização entre os dois

1 Uma outra interpretação desse diferencial de utilização pode ser encontrada em Nyman (1999). Segundo o autor, o valor do seguro resulta não só da proteçẫo ao risco como também da possibilidade de viabilizar acesso a serviços de saúde que não seriam factíveis na ausência de seguro - denominado por Nyman (1999) de motivo acesso. Desse modo, uma outra forma de interpretar a sobreutilização dos cuidados de saúde a partir dessa discussão proposta por Nyman (1999) sugere que o diferencial de utilização pode ser resultante de uma alteração no conjunto de cestas de cuidados factíveis para os consumidores na presença de seguro-saúde em relação à situação de ausência de seguro-saúde. Essa interpretação é distinta da problematizada nesse artigo, na qual supomos que o diferencial de utilização pode ser resultante do diferencial de acesso em termos de presença de barreiras/ dificuldades à utilização e não restrição orçamentária. A forma de mensuração do diferencial não nos permite identificar essas duas interpretaçốes. 
setores incorporando uma variável proxy para o acesso aos serviços de saúde de modo a minimizar o diferencial de acesso entre os dois setores.

A estimativa é realizada através de uma análise contrafactual, em que a diferença entre a utilização média estimada dos indivíduos que possuem plano e a utilização média estimada para esses mesmos indivíduos caso não possuíssem plano privado nos fornece o valor do diferencial de utilização no sistema de saúde suplementar. A fim de controlar o problema de endogeneidade entre a escolha de ter plano de saúde e a utilização de serviços de saúde realizamos três procedimentos. No primeiro procedimento, estimamos a utilização em duas etapas: na primeira etapa, implementamos a correção do viés de autosseleção considerando as variáveis socioeconômicas (renda familiar per capita e ocupação do chefe de família) como instrumentos para a decisão de ter plano de saúde; na segunda etapa, estimamos a utilização dos serviços de saúde através do método contrafactual considerando a probabilidade de ter plano de saúde como variável de controle. No segundo procedimento, separamos, através do método de Matching proposto por Abadie e Imbens (2006) a amostra de indivíduos entre grupo de tratamento (possui plano de saúde) e grupo de comparação (não possui plano de saúde). Identificados esses dois grupos, realizamos a análise contrafactual estimando a utilização dos serviços de saúde nos dois grupos. O método do matching permite-nos identificar indivíduos com características médias semelhantes aos tratados, eliminando, portanto, o viés de seleção amostral. No terceiro procedimento, estimamos o diferencial de utilização restringindo o grupo de indivíduos que têm plano de saúde àqueles que têm plano privado público. Nesse caso, é razoável supor que a decisão de ter plano de saúde não é uma decisão do empregado, mas sim do empregador, o que torna a decisão de ter plano exógena à decisão de utilização. Em geral, quando existe oferta de seguro privado para funcionários públicos no Brasil, a adesão é compulsória.

Utilizamos os dados da PNAD de 1998 e 2003, realizada pelo IBGE (Instituto Brasileiro de Geografia e Estatística). A pesquisa fornece uma ampla variedade de informações individuais e domiciliares. Em 1998 e em 2003, foi a campo um suplemento que indaga a respeito das características de saúde dos moradores.

As categorias de cuidado médico selecionadas são: (i) o número de consultas realizadas nos últimos 12 meses e (ii) o número de dias internado na última internação, nos últimos 12 meses.

Os principais resultados apontam um diferencial positivo de utilização no setor de saúde suplementar para ambos os tipos de cuidado nos dois anos analisados. Para consultas médicas, o diferencial foi estimado em cerca de $25 \%$ quando comparamos os indivíduos com qualquer plano em relação ao que utilizariam se estivessem no 
SUS. Para dias de internação, a estimativa variou de 9 a $26 \%$, dependendo do método implementado. A interpretação desses resultados como uma medida do risco moral sugere que os contratos no sistema suplementar podem não estar desenhados adequadamente. A sociedade pode estar incorrendo em perdas de bem-estar, uma vez que os indivíduos com cobertura privada escolhem mais cuidado do que escolheriam na ausência de seguro, e as seguradoras, por sua vez, antecipam esse comportamento elevando o prêmio. Em consequência, uma parcela menor da população tem acesso à cobertura privada. Uma mudança institucional importante envolveria a incorporação de mecanismos de divisão de custos com consumidores de forma mais generalizada ou até mesmo a adoção de práticas de cuidado gerenciado. ${ }^{2}$

\section{O RISCO MORAL}

O mercado de bens e serviços de saúde é um mercado particular quando comparado aos demais. Ressaltamos dois aspectos: o ambiente de incerteza e a presença de informação assimétrica. A incerteza está presente em dois momentos da decisão de consumo individual. Primeiro, existe incerteza quanto à necessidade do uso dos serviços médicos, uma vez que em sua maior parte este uso é decorrente de choques estocásticos. Segundo, existe incerteza quanto ao diagnóstico clínico e quanto à eficácia do tratamento. Além disso, a distribuição das despesas médicas tanto na população quanto ao longo do ciclo de vida dos indivíduos não é normal, assumindo valores muito altos para poucos episódios.

A assimetria de informações está presente na relação entre os três agentes envolvidos no estabelecimento de um contrato de seguro de saúde: o consumidor, a seguradora e o provedor dos bens e serviços de saúde, e pode resultar em problemas de agência. Os consumidores e a seguradora correspondem à demanda de mercado, podendo o sistema de seguros ser de natureza pública ou privada, enquanto os provedores correspondem à oferta de mercado.

A relação entre o segurador, seja com o provedor, seja com o consumidor, apresenta problemas de risco moral. ${ }^{3}$ Com o provedor, o problema ocorre na medida em que este pode induzir uma sobreutilização dos serviços, dado que possui maior quantida-

2 Segundo as informações da PNAD de 2003, cerca de $27 \%$ da população coberta por planos privados possui planos que cobram algum valor, além da mensalidade, pelos atendimentos prestados.

3 Além da presença de risco moral, a assimetria informacional entre o segurador e os consumidores pode resultar também em problemas de seleção adversa e/ou prática de screening pelas seguradoras. A seleção adversa pode ocorrer na medida em que a seguradora, ao não observar todos os atributos de risco, precifica o seguro através do risco médio da população. Esse sistema de precificação resulta em seleção desfavorável de consumidores. A prática do screening pode ocorrer se as seguradoras resolverem implementar mecanismos que determinem uma seleção favorável de consumidores. 
de de informação que os financiadores/seguradores. Essa indução de demanda pode ocorrer tanto para elevar os rendimentos diretos dos provedores quanto para reduzir a incerteza do diagnóstico, e com isso obter também ganhos de reputação. Entre o consumidor e o segurador, o risco moral pode ocorrer na presença de seguro. Neste caso, os consumidores tendem a sobreutilizar os serviços, já que o custo marginal do produto demandado é zero ou próximo de zero ${ }^{4}$.

A evidência teórica e empírica já apontou, em diversos estudos (CUTLER e ZECKHAUSER, 2000; NEWHOUSE, 1993; MANNING et al. 1987; CAMERON, 1988; SAPELLI e VIAL, 2003; CHIAPORRI, 1998) que o risco moral é um dos principais problemas no mercado de seguros de saúde. O risco moral gera perdas de bem-estar na medida em que parte da população não está apta a adquirir um plano ou seguro de saúde devido ao aumento dos custos com consequente elevação dos preços. ${ }^{5}$ Esse efeito ocorre porque a seguradora antecipa o comportamento dos indivíduos elevando os preços do seguro, excluindo uma parcela da população.

Existe, portanto, um trade-off entre a diluição do risco na população (possibilitando a transferência de renda entre os diferentes estados da natureza) e a introdução de incentivos adequados. Ou seja, quanto mais extenso for o grupo de procedimentos ofertado pelo seguro, implicando uma divisão de riscos mais ampla, maior pode ser a perda de bem-estar decorrente do risco moral, dado que os indivíduos escolhem receber mais cuidado (risco moral) e os provedores ofertam mais cuidado (indução de demanda) (CUTLER; ZECKHAUSER, 2000). Entre os mecanismos usuais para minimizar o risco moral no comportamento do consumidor, podemos citar os mecanismos de divisão de custos, como copagamentos, cosseguros e franquias.

A principal referência na literatura empírica é o estudo coordenado por Newhouse entre 1971 e 1982 denominado RAND Health Insurance Study, o qual se constitui de um experimento longitudinal que tem como um de seus objetivos analisar o comportamento do indivíduo diante de diferentes arranjos de seguro-saúde. Um dos principais resultados desse trabalho é a mensuração da elasticidade-preço da demanda por serviços de saúde. A utilização dos serviços diminui à medida que os consumidores desembolsam diretamente uma parcela do pagamento. Manning et al.(1987) estimam, para a população do experimento, valores entre $-0,1$ e $-0,2$,

4 Na presença de copagamento o custo marginal é positivo, mas é inferior ao valor real dos serviços. O risco moral é decrescente com o grau de cobertura (NEWHOUSE, 1993).

5 Embora exista um consenso na literatura de economia da saúde sobre os efeitos de perda de bem-estar observados na presença de risco moral, em circunstâncias particulares é possível identificar um efeito positivo. Pauly e Held (1990), por exemplo, demonstram que em situações nas quais existem imperfeições na geração de renda das seguradoras na oferta de determinados serviços, mesmo que o serviço seja custo efetivo, a oferta de cobertura não será total. Nesses casos, a presença de risco moral pode aproximar o nível de utilização observado ao nível ótimo, tendo, portanto, um efeito positivo no bemestar individual e social. 
dependendo do tipo de cuidado considerado e da variação na taxa de copagamento. $\mathrm{Na}$ literatura empírica não existe um consenso acerca dessa magnitude, os valores encontrados variam de $-0,14$ a $-1,5$ dependendo do tipo de cuidado considerado e do método de estimação (CUTLER; ZECKHAUSER, 2000).

Uma dificuldade dos trabalhos empíricos que analisam o problema de risco moral é a presença da endogeneidade entre a escolha de adquirir plano de saúde e a utilização dos serviços de saúde. Essa endogeneidade deve-se ao fato de a decisão de adquirir plano ser realizada com base na expectativa de utilização dos serviços. Dessa forma, características específicas dos indivíduos que adquirem planos podem influenciar sua utilização, resultando em um problema de viés de seleção amostral. As bases longitudinais constituem uma forma de solucionar o problema da endogeneidade. Essas bases acompanham o mesmo indivíduo ao longo do tempo, identificando o impacto das mudanças nas características individuais e nas características dos planos ou seguros sobre a utilização. Além disso, é possível identificar o momento de adesão ao plano e controlar o estado de saúde do indivíduo.

Cameron et al. (1988) são os pioneiros no desenvolvimento de um modelo que interage a demanda por seguro de saúde e a utilização do cuidado de saúde. A implementação empírica do trabalho, a partir de dados cross-section do Australian Health Survey de 1977-78, consiste em utilizar variáveis instrumentais da escolha do seguro de saúde como variável dependente do modelo de utilização do cuidado de saúde. É estimado um modelo para a probabilidade de ter um determinado tipo de seguro, ${ }^{6}$ e o valor predito da probabilidade é a variável instrumental da escolha de ter seguro sendo incluída no modelo de utilização. O resultado mostra que a utilização do cuidado é maior para aqueles que possuem uma cobertura mais ampla, indicando a presença de risco moral.

Sapelli e Vial (2003) estimam risco moral e seleção adversa no sistema de saúde chileno. Para mensurar a presença de risco moral, compara-se a utilização do serviço de saúde na presença do seguro com a utilização caso o indivíduo não houvesse adquirido aquele seguro. São analisadas duas variáveis de utilização do cuidado médico: número de consultas médicas e número de dias internado. O risco moral não é encontrado para dias internado, mas é encontrado para consultas médicas.

Barros et al. (2008) estimam o impacto da cobertura de plano de saúde para servidores públicos e seus dependentes no sistema de saúde português sobre a demanda de três serviços de saúde (quantidade de consultas, de exames de sangue e urina e

6 Quatro tipos de seguro de saúde são considerados: cobertura do seguro Medibank, cobertura de seguro privado, cobertura gratuita pelo governo por motivo de baixa renda, imigrante recente e desemprego, cobertura gratuita pelo governo por motivo de pensão por idade ou incapacidade e veterano ou família de veterano. 
probabilidade de uma consulta ao dentista) usando a técnica de matching. Os autores argumentam que no contexto da cobertura de plano de saúde compulsória e oferecida através do vínculo empregatício, a cobertura de seguro é exógena à utilização dos serviços de saúde. Os resultados indicaram a presença de risco moral na realização de exames. Já os efeitos sobre consultas médicas e probabilidade de consulta ao dentista apresentaram impactos não estatisticamente diferentes de zero.

Utilizando dados longitudinais durante dois anos na França, Chiappori et al. (1998) avaliam a presença de risco moral na utilização do cuidado médico. $\mathrm{O}$ trabalho analisa os impactos da divisão de custos entre seguradores e pacientes através da alteração na taxa de copagamento. A análise considera apenas a decisão de realizar ao menos uma consulta, para três tipos de cuidado: consultas realizadas no consultório, consultas realizadas em casa e consultas no consultório de um médico especialista. Os principais resultados indicam a presença de risco moral para consultas em casa, mas não para consultas no consultório, sugerindo risco moral na demanda pelo cuidado médico quando custos não-monetários também são importantes. Ou seja, custos como de deslocamento e tempo podem representar uma importante fração do custo total considerado pelo consumidor, tendendo a diminuir o impacto da mudança de preços sobre a utilização.

No Brasil, existem poucos estudos que investigam empiricamente a presença do risco moral no sistema de saúde. O trabalho desenvolvido por Stancioli (2002), utilizando as informações da PNAD de 1998 aponta a presença de risco moral. A escassez desses trabalhos deve-se, provavelmente, à restrita disponibilidade de bases que contemplem dados de utilização do serviço de saúde associados a características individuais como cobertura por algum plano de saúde, características socioeconômicas, de estado de saúde, entre outras.

A regulamentação do setor de saúde suplementar brasileiro, de 1998, não apresenta nenhuma restrição ao uso de mecanismos de divisão de custos (como, por exemplo, copagamento) e o cuidado gerenciado. ${ }^{7}$ Mesmo não havendo restrições, esses mecanismos ainda são pouco difundidos no setor privado e inexistentes no setor público. Segundo dados da PNAD de 2003, 30\% dos indivíduos com plano de saúde pagam, além da mensalidade, algum valor pelos atendimentos a que têm direito, ou seja, pequena parte da população com plano está sujeita a algum mecanismo de divisão de custos. ${ }^{8}$ No setor de saúde suplementar, o único mecanismo de racionalização da

7 O termo Cuidado Gerenciado refere-se, de uma forma genérica, às práticas adotadas para administrar os serviços prestados pelos provedores contratados pelos planos e seguradoras de saúde.

8 As perguntas da PNAD são insuficientes para permitir uma comparação entre os grupos de indivíduos com plano de saúde sujeitos a mecanismos de divisão de custos e os indivíduos com plano de saúde sem mecanismos de divisão de custos. O nível de detalhamento não informa sobre quais tipos de serviços o copagamento incide e de que forma. 
utilização que é amplamente adotado é a delimitação da rede de provedores. Segundo os dados da PNAD 2003, 93\% dos titulares declaram que o plano oferece lista de médicos e que $81 \%$ possuem rede de atendimento própria, limitando, portanto, a escolha de provedores.

No caso de sistemas públicos, a introdução desses mecanismos financeiros é pouco usual e, quando existe, incide apenas sobre alguns grupos de serviços. A dificuldade de implementação de mecanismos de divisão de custos em sistemas públicos, ou seja, a racionalização do uso dos serviços através de custos monetários impostos aos pacientes, reside na questão distributiva. Os impactos desses mecanismos são distintos, dependendo do nível de renda. Esses sistemas, em geral, utilizam mecanismos de racionalização indiretos/não-monetários. No caso do sistema público brasileiro, os mecanismos de racionalização da utilização não estão implementados institucionalmente, embora, na prática, ocorra a restrição da utilização através de filas de espera.

\section{MODELO EMPÍRICO}

A abordagem empírica proposta neste trabalho consiste em uma análise contrafactual na qual estimamos a utilização dos serviços de saúde para dois segmentos do sistema de saúde brasileiro, considerando o status de cobertura de plano de saúde dos indivíduos. A utilização dos serviços de saúde é estimada em duas subamostras separadas: primeiro para a subamostra de indivíduos com plano de saúde e segundo para a subamostra de indivíduos sem plano de saúde. É mensurada através de dois indicadores: número de consultas médicas realizadas nos últimos doze meses e número de dias internado na última internação realizada nos últimos 12 meses. ${ }^{9}$ As consultas médicas e o número de dias internado representam diferentes tipos de cuidado de saúde e diferentes processos de decisão. No caso de consultas médicas, a decisão de consumir o serviço é, na maior parte, realizada pelo próprio indivíduo, enquanto no caso da internação a decisão é usualmente tomada pelos médicos.

Para estimar a utilização dos serviços médicos, utilizamos modelos de dados de contagem. Essa escolha justifica-se na medida em que a utilização é mensurada

9 A estimação do diferencial de utilização entre os setores público e privado não considera a possibilidade de um indivíduo que tem plano ser financiado pelo setor público. A hipótese que estamos fazendo é de que os indivíduos que possuem plano realizam os seus serviços através do setor privado. A análise descritiva da variável de internação mostra que, entre as pessoas que estiveram internadas nos últimos 12 meses e possuem plano de saúde, existe um percentual de $16 \%$ que tiveram sua última internação financiada pelo SUS. Infelizmente, não há como corrigir esse problema, pois a exclusão desses indivíduos da amostra pode criar um viés. Ademais, mesmo que a internação seja financiada pelo SUS, a sua ocorrência está associada à presença de plano de saúde. 
através do número de visitas médicas e do número de dias internado, os quais consistem em valores não-negativos e inteiros. O modelo de Poisson é o modelo básico no arcabouço dos modelos de dados de contagem. Um modelo alternativo ao de Poisson é o Binomial Negativo, no qual a distribuição permite mais flexibilidade na modelagem da variância. O Binomial Negativo é o modelo paramétrico padrão para o caso de sobredispersão dos dados, ou seja, o caso em que a variância condicional excede a média. A fim de verificar se os dados são sobredispersos, efetuamos o teste da razão de verossimilhança, que indica a sobredispersão dos dados. A estimativa do diferencial consiste em uma análise contrafactual, dada pela subtração entre (i) o número esperado de serviços consumido pelo indivíduo $i$ após adquirir um plano de saúde e (ii) o número esperado de serviços que o indivíduo $i$ poderia consumir, caso ele não adquirisse o plano de saúde.

Temos, portanto, que:

$$
\text { Diferencial }=E\left(y_{S} / X, D_{S}=1\right)-E\left(y_{S} / X, D_{S}=0\right)
$$

Onde $y_{s}$ é a utilização da subamostra com plano de saúde; $X$ é o vetor de atributos dos indivíduos com plano de saúde; $D_{S}=1$ são indivíduos que possuem algum plano de saúde (sistema suplementar) e $D_{S}=0$ são indivíduos que não possuem nenhum tipo de plano de saúde. No caso de um valor positivo, o valor esperado da utilização é maior para aqueles que adquirem um plano do que para os mesmos indivíduos caso não tivessem comprado um plano de saúde.

\subsection{O Problema da Endogeneidade entre a Decisão de Ter Plano e a Decisão de Utilização}

Como já mencionado, a dificuldade de se obter uma medida de risco moral decorre da endogeneidade entre a decisão de compra de plano de saúde e a decisão de utilização. É razoável supor que indivíduos com expectativa de utilização de serviços de saúde apresentem maior propensão a comprar plano de saúde. Essa endogeneidade entre as duas decisões acaba resultando em uma autosseleção dos indivíduos, gerando um problema de viés de seleção amostral.

A fim de controlar o problema de endogeneidade entre a escolha de ter plano de saúde e a utilização de serviços de saúde, realizamos três procedimentos. No primeiro procedimento (procedimento 1) estimamos a utilização em duas etapas: na primeira etapa implementamos a correção do tipo Heckman considerando as variáveis socioeconômicas (decis de renda familiar per capita e ocupação do chefe de família) como instrumentos para a decisão de ter plano de saúde; na segunda etapa, estimamos a utilização dos serviços de saúde através do método contrafactual, considerando a 
probabilidade de ter plano de saúde como variável de controle. ${ }^{10}$ Esse procedimento é suficiente para controlar a endogeneidade se variáveis socioeconômicas forem suficientes para separar as duas decisões. Para testar essa hipótese, comparamos as estimações da probabilidade de ter plano de saúde nas situações de inclusão e exclusão dessas variáveis socioeconômicas. A análise do valor do pseudo- $\mathrm{R}^{2}$ confirma que essas variáveis são fundamentais para explicar a decisão de ter plano. No modelo de utilização, por outro lado, essas variáveis socioeconômicas não são estatisticamente significativas para explicar a decisão de utilização. ${ }^{11}$

No segundo procedimento (procedimento 2), separamos, através do método de Matching proposto por Abadie e Imbens (2006), a amostra de indivíduos entre grupo de tratamento (possui plano de saúde) e grupo de comparação (não possui plano de saúde). Identificados esses dois grupos, realizamos a análise contrafactual, estimando a utilização dos serviços de saúde nos dois grupos. O método do macthing permite-nos identificar indivíduos com características médias semelhantes aos tratados procurando eliminar, o viés de seleção amostral.

Por último, no terceiro procedimento (procedimento 3), estimamos o diferencial de utilização restringindo o grupo de indivíduos que têm plano de saúde àqueles que têm plano de saúde de instituição de assistência de servidor público. Nesse caso, é razoável supor que a decisão de ter plano de saúde não é uma decisão do empregado, mas sim do empregador, o que torna a decisão de ter plano exógena à decisão de utilização. Em geral, quando existe oferta de plano de saúde para funcionários públicos no Brasil a adesão é compulsória. Esse procedimento segue o proposto por Barros et al. (2008) em que os autores, ao analisar risco moral no sistema de saúde português, solucionam o problema de endogeneidade ao comparar a utilização dos indivíduos que possuem plano $\mathrm{ADSE}^{12}$ (proteção social aos funcionários e agentes da administração pública) em relação aos usuários apenas do sistema público português. Os indivíduos do grupo de comparação foram identificados segundo o método do matching proposto no procedimento 2 .

10 A utilização de variáveis socioeconômicas como instrumentos para a decisão de ter plano de saúde já foi anteriormente utilizada por outros autores (CAMERON et al., 1988).

11 No modelo estimado considerando as variáveis socioeconômicas o pseudo- $\mathrm{R}^{2}$ foi de 0,33 , ao passo que quando excluímos estas variáveis o valor dessa estatística se reduz para 0,24. Esse resultado é válido para os dois anos analisados. Os valores das log-verossimilhança referentes aos dois modelos de utilização estimados são extremamente próximos. Esses resultados evidenciam que as variáveis socioeconômicas conjuntamente não alteram a decisão de utilização. Vale ainda lembrar que as variáveis socioeconômicas são incluídas não linearmente na equação de utilização através da probabilidade de ter plano de saúde.

12 ADSE - Direção Geral de Proteção Social aos Funcionários e Agentes da Administração Pública. 


\subsection{Banco de Dados e Análise Descritiva}

Nesta seção, descrevemos o banco de dados e as principais variáveis incluídas na estimação.

\subsubsection{Banco de Dados}

A base de dados utilizada é a Pesquisa Nacional por Amostra de Domicílios dos anos de 1998 e 2003, realizada pelo IBGE. A pesquisa possui um suplemento inédito com informações a respeito das características de saúde dos moradores.

A seguir, descrevemos o efeito esperado das variáveis do modelo de utilização.

Variáveis explicativas usadas nas equações de utilização:

1. Grupos de Idade. Consideramos oito grupos de idade: de 0 a 1 ano, de 2 a 9 anos, de 10 a 25 anos, de 26 a 35 anos, de 36 a 45 anos, de 46 a 55 anos, de 56 a 65 anos e mais de 65 anos. O grupo de referência é de 0 a 1 ano de idade. Essa segmentação procura contemplar diferentes grupos de risco, com padrões de utilização homogêneos.

2. Gênero. A variável sexo busca controlar para a diferença de necessidade de utilização do serviço de saúde entre homens e mulheres. Espera-se que mulheres utilizem mais o serviço de saúde que homens. A referência adotada são as mulheres.

3. Área de residência. As dummies para área de residência (região metropolitana, urbana e rural) têm como objetivo captar diferentes densidades populacionais. Espera-se que áreas de baixa densidade tenham efeito negativo tanto na utilização dentro do segmento dos planos de saúde quanto do segmento da população coberta apenas pelo SUS. O efeito está associado ao custo de tempo de viajar para utilizar os serviços e à reduzida oferta de provedores nessas áreas. A padronização é pela região rural.

4. Unidades da Federação. As dummies das Unidades da Federação têm como objetivo controlar as diferenças na oferta e acesso aos serviços de saúde. A unidade da federação de referência é o Estado de São Paulo.

5. Anos de estudo. Quanto maior a escolaridade, maior deve ser a utilização do serviço de saúde, uma vez que os indivíduos mais escolarizados têm maior capacidade de valorizar o cuidado recebido. $O$ grau de informação tende a impactar principalmente a utilização preventiva. Desse modo, o efeito esperado é diferente 
para os modelos de consultas e de internação. A categoria de referência usada é de 15 anos ou mais de estudo.

6. Presença de criança, pessoa idosa e mulher em idade fértil na familia. O controle da presença de algum membro da família caracterizado como grupo de risco pode alterar a utilização porque aumenta a aversão ao risco e dessa forma pode elevar o cuidado preventivo.

7. Sanide autoavaliada. A pergunta sobre saúde autoavaliada refere-se a uma medida do estado de saúde autoavaliado. São cinco categorias de resposta - muito bom, bom, regular, ruim ou muito ruim. É esperado que, quanto pior for esse indicador de saúde, maior será a utilização dos serviços de saúde. Agrupamos as categorias de resposta em uma variável binária em que indivíduos que reportam saúde muito boa e boa foram considerados saudáveis, e indivíduos que reportaram saúde regular, ruim e muito ruim foram considerados com estado de saúde precário. A categoria de referência nesse caso é a saúde ruim.

8. Presença de doença crônica. Foram incluídas 12 dummies para indicar a presença de doença crônica. A presença de determinada doença crônica deve aumentar a utilização do serviço de saúde (fator de risco).

9. Número de componentes na familia. Variável que indica o número de componentes na família do indivíduo.

10. Acesso. A variável de acesso foi construída com o objetivo de se tentar controlar o diferencial de acesso aos serviços de saúde entre a população com plano e a população com cobertura apenas do sistema público de saúde. A variável de acesso é igual a um (1) se o indivíduo teve problema de acesso, e zero (0) em caso contrário. A construção dessa variável consiste em uma combinação de três questôes referentes à utilização dos serviços de saúde. Variável V1350: Nas duas últimas semanas, procurou algum lugar, serviço ou profissional de saúde para atendimento relacionado à própria saúde? Caso a resposta seja afirmativa: variável V1354: Nessa primeira vez que procurou atendimento de saúde nas duas últimas semanas foi atendido? Sim (não houve problema de acesso). Não (houve problema de acesso). Caso a resposta a V1350 seja negativa, ir para variável V1368: Nas duas últimas semanas, por que motivo não procurou atendimento de saúde? Não houve necessidade (não houve problema de acesso). Categorias de resposta de 02 a 10, por ex: não tinha dinheiro, horário incompatível (houve problema de acesso). 
11. Qualidade. A variável proxy de controle da qualidade refere-se a uma medida sobre como o indivíduo considera o atendimento de saúde recebido. São cinco categorias de resposta: muito bom, bom, regular, ruim ou muito ruim. Essa pergunta refere-se apenas àqueles indivíduos que receberam algum atendimento de saúde no último ano. Agrupamos as categorias de resposta em uma variável categórica atribuindo aos indivíduos que não receberam atendimento no último ano o valor zero; valor um (1) para aqueles que reportam o atendimento recebido como regular, ruim e muito ruim e valor dois (2) para aqueles que reportam $\mathrm{o}$ atendimento recebido como muito bom e bom.

12. Probabilidade de ter um plano de sanide. Quanto maior a probabilidade de possuir um plano de saúde, maior deve ser a utilização dos serviços de saúde.

13. Idade do chefe de familia. Variável contínua da idade do chefe de família.

\subsubsection{Análise Descritiva}

A Tabela 1 sistematiza o número médio de consultas e dias internado na última internação entre indivíduos com plano, com plano de instituição de assistência de servidor público, doravante abreviados (PIASP) e indivíduos sem plano de saúde. Observamos que os indivíduos com plano de saúde e indivíduos com PIASP têm média e desvio padrão de consultas superiores aos daqueles sem plano. ${ }^{13} \mathrm{~A}$ média de dias internado na última internação também é maior entre os com plano, sendo esta diferença pouco acentuada. Um aspecto que chama atenção é que para indivíduos com PIASP o número médio de dias de internação é bastante superior à média dos demais grupos. Essa diferença provavelmente se deve à composição do risco das duas populações: a população que tem plano PIASP apresenta distribuição de idade com maiores proporções nos grupos etários mais elevados (Tabelas VII e VIII do Anexo 4).

13 O teste de médias indica que as médias são diferentes ao nível de significância de $1 \%$. 


\section{TABELA I - NÚMERO MÉDIO DE CONSULTAS E DIAS DE INTERNAÇÃO NOS ÚLTIMOS 12 MESES}

\begin{tabular}{|c|c|c|c|c|c|c|}
\hline \multirow[t]{2}{*}{ ANO } & \multicolumn{3}{|c|}{ Consultas médicas } & \multicolumn{3}{|c|}{ Dias de internação } \\
\hline & $\begin{array}{l}\text { Com plano de } \\
\text { saúde }\end{array}$ & PIASP & $\begin{array}{l}\text { Sem plano de } \\
\text { saúde }\end{array}$ & $\begin{array}{l}\text { Com plano de } \\
\text { saúde }\end{array}$ & PIASP & $\begin{array}{l}\text { Sem plano de } \\
\text { saúde }\end{array}$ \\
\hline 1998 & $3,08(4,71)$ & $2,72(4,27)$ & $1,75(3,63)$ & $0,45(4,03)$ & $0,53(4,67)$ & $0,42(3,80)$ \\
\hline 2003 & $3,55(5,07)$ & $2,28(4,78)$ & $2,17(3,94)$ & $0,45(4,17)$ & $0,54(4,35)$ & $0,40(3,92)$ \\
\hline
\end{tabular}

Fonte: Elaboração própria a partir de dados da PNAD de 1998 e 2003.

Para analisar como as variáveis de risco influenciam as chances de utilizar os serviços, estimamos um modelo probit para a probabilidade de realizar ao menos uma consulta e ficar pelo menos um dia internado. As variáveis de controle usadas foram as mesmas do modelo de utilização.

A Tabela 2 sistematiza a probabilidade média de utilizar ao menos uma vez o cuidado de saúde.

TABELA 2 - PROBABILIDADE MÉDIA DE UTILIZAR AO MENOS UMA VEZ O CUIDADO DE SAÚDE

\begin{tabular}{ccccccccc}
\hline ANO & \multicolumn{3}{c}{ Consultas médicas } & & \multicolumn{3}{c}{ Internação } \\
\cline { 2 - 3 } & $\begin{array}{c}\text { Com plano de } \\
\text { saúde }\end{array}$ & PIASP & $\begin{array}{c}\text { Sem plano de } \\
\text { saúde }\end{array}$ & & $\begin{array}{c}\text { Com plano de } \\
\text { saúde }\end{array}$ & PIASP & $\begin{array}{c}\text { Sem plano de } \\
\text { saúde }\end{array}$ \\
\hline 1998 & $0,65(0,20)$ & $0,69(0,18)$ & $0,51(0,22)$ & & $0,07(0,07)$ & $0,07(0,07)$ & $0,07(0,08)$ \\
2003 & $0,73(0,18)$ & $0,77(0,15)$ & $0,59(0,20)$ & & $0,07(0,07)$ & $0,08(0,07)$ & $0,07(0,07)$ \\
\hline
\end{tabular}

Fonte: Elaboração própria a partir de dados da PNAD de 1998 e 2003.

A probabilidade de realizar ao menos uma consulta no ano é maior entre os indivíduos com plano e PIASP em comparação àqueles sem plano. Quando consideramos a probabilidade de internação, não observamos nenhuma diferença significativa da probabilidade média. 
TABELA 3 - PROBABILIDADE MÉDIA DE CONSULTAR AO MENOS UMA VEZ, NO ANO, SEGUNDO ATRIBUTOS DE RISCO, 1998 E 2003

\begin{tabular}{lccccccc}
\hline ANO & \multicolumn{4}{c}{1998} & & \multicolumn{3}{c}{2003} \\
\cline { 2 - 3 } & Com plano & Com PIASP & Sem plano & & Com plano & Com PIASP & Sem plano \\
\hline Homem & $0,58(0,20)$ & $0,60(0,48)$ & $0,44(0,20)$ & & $0,65(0,19)$ & $0,69(0,43)$ & $0,51(0,20)$ \\
Mulher & $0,72(0,18)$ & $0,73(0,43)$ & $0,59(0,20)$ & $0,80(0,15)$ & $0,82(0,37)$ & $0,68(0,18)$ \\
De 0 a 1 ano & $0,86(0,11)$ & $0,86(0,34)$ & $0,74(0,15)$ & & $0,91(0,08)$ & $0,92(0,26)$ & $0,82(0,12)$ \\
De 2 a 9 anos & $0,68(0,16)$ & $0,70(0,45)$ & $0,53(0,17)$ & $0,77(0,14)$ & $0,78(0,40)$ & $0,63(0,16)$ \\
De 10 a 25 anos & $0,55(0,20)$ & $0,56(0,49)$ & $0,40(0,19)$ & & $0,63(0,18)$ & $0,66(0,47)$ & $0,49(0,19)$ \\
De 26 a 35 anos & $0,64(0,19)$ & $0,67(0,46)$ & $0,51(0,20)$ & $0,71(0,17)$ & $0,76(0,42)$ & $0,58(0,19)$ \\
De 36 a 45 anos & $0,66(0,19)$ & $0,71(0,45)$ & $0,53(0,21)$ & $0,73(0,17)$ & $0,77(0,41)$ & $0,61(0,20)$ \\
De 46 a 55 anos & $0,70(0,20)$ & $0,74(0,43)$ & $0,59(0,23)$ & $0,77(0,17)$ & $0,81(0,39)$ & $0,66(0,21)$ \\
De 56 a 65 anos & $0,75(0,20)$ & $0,76(0,42)$ & $0,65(0,23)$ & & $0,81(0,17)$ & $082(0,38)$ & $0,71(0,21)$ \\
Mais de 65 & $0,79(0,19)$ & $0,81(0,38)$ & $0,71(0,21)$ & & $0,85(0,15)$ & $0,87(0,33)$ & $0,77(0,19)$ \\
Saúde autoavaliada boa & $0,62(0,19)$ & $0,62(0,19)$ & $0,45(0,19)$ & & $0,70(0,18)$ & $0,73(0,43)$ & $0,54(0,19)$ \\
Saúde autoavaliada ruim & $0,84(0,15)$ & $0,84(0,15)$ & $0,73(0,18)$ & $0,88(0,13)$ & $0,89(0,30)$ & $0,78(0,17)$ \\
\hline
\end{tabular}

Fonte: Elaboração própria a partir de dados da PNAD de 1998 e 2003.

TABELA 4 - PROBABILIDADE MÉDIA DE AO MENOS UMA INTERNAÇÃO, NO ANO, SEGUNDO ATRIBUTOS DE RISCO, 1998 E 2003

\begin{tabular}{|c|c|c|c|c|c|c|}
\hline \multirow[t]{2}{*}{ ANO } & \multicolumn{3}{|c|}{1998} & \multicolumn{3}{|c|}{2003} \\
\hline & Com plano & Com PIASP & Sem plano & Com plano & Com PIASP & Sem plano \\
\hline Homem & $0,05(0,06)$ & $0,06(0,06)$ & $0,05(0,06)$ & $0,05(0,06)$ & $0,07(0,06)$ & $0,05(0,06)$ \\
\hline Mulher & $0,08(0,08)$ & $0,09(0,08)$ & $0,09(0,09)$ & $0,08(0,08)$ & $0,09(0,07)$ & $0,09(0,09)$ \\
\hline De 0 a 1 ano & $0,11(0,08)$ & $0,08(0,04)$ & $0,11(0,08)$ & $0,11(0,08)$ & $0,11(0,06)$ & $0,11(0,08)$ \\
\hline De 2 a 9 anos & $0,04(0,05)$ & $0,05(0,04)$ & $0,04(0,05)$ & $0,04(0,05)$ & $0,06(0,04)$ & $0,04(0,05)$ \\
\hline De 10 a 25 anos & $0,05(0,05)$ & $0,05(0,04)$ & $0,05(0,06)$ & $0,05(0,05)$ & $0,05(0,03)$ & $0,05(0,06)$ \\
\hline De 26 a 35 anos & $0,08(0,07)$ & $0,09(0,06)$ & $0,08(0,08)$ & $0,08(0,07)$ & $0,09(0,06)$ & $0,08(0,08)$ \\
\hline De 36 a 45 anos & $0,06(0,06)$ & $0,07(0,06)$ & $0,07(0,07)$ & $0,06(0,06)$ & $0,08(0,06)$ & $0,07(0,07)$ \\
\hline De 46 a 55 anos & $0,07(0,07)$ & $0,08(0,07)$ & $0,07(0,07)$ & $0,07(0,07)$ & $0,08(0,07)$ & $0,07(0,07)$ \\
\hline De 56 a 65 anos & $0,10(0,10)$ & $0,12(0,10)$ & $0,11(0,09)$ & $0,10(0,10)$ & $0,11(0,08)$ & $0,11(0,09)$ \\
\hline Mais de 65 & $0,15(0,12)$ & $0,17(0,12)$ & $0,15(0,11)$ & $0,15(0,12)$ & $0,16(0,11)$ & $0,15(0,11)$ \\
\hline Saúde autoavaliada boa & $0,05(0,05)$ & $0,05(0,03)$ & $0,05(0,05)$ & $0,05(0,05)$ & $0,06(0,04)$ & $0,05(0,05)$ \\
\hline Saúde autoavaliada ruim & $0,16(0,10)$ & $0,18(0,10)$ & $0,15(0,10)$ & $0,16(0,10)$ & $0,17(0,10)$ & $0,15(0,10)$ \\
\hline
\end{tabular}

Fonte: Elaboração própria a partir de dados da PNAD de 1998 e 2003. 
Os dados das Tabelas 3 e 4 mostram a probabilidade estimada de utilizar ao menos uma vez o cuidado de saúde segundo a cobertura de plano de saúde e os atributos de risco: sexo, idade e estado de saúde. Com relação ao gênero, o resultado indica que as mulheres têm maior probabilidade de utilizar os dois tipos de cuidado independente da cobertura de plano de saúde. Este resultado pode representar tanto maior aversão ao risco quanto maior taxa de risco. Em relação à idade, observamos o padrão da curva em $\mathrm{U}$, com utilização maior para os grupos extremos e relação monotônica crescente a partir de 25 anos. Quanto à variável de saúde autoavaliada, observamos uma grande diferença na probabilidade de utilização do cuidado médico entre aqueles que avaliam seu estado de saúde como bom e ruim.

\subsubsection{Ajustamento do Matching}

Para avaliar o grau de ajustamento do matching utilizado no procedimento 2 como forma de correção da endogeneidade apresentamos nas Tabelas V a VIII do anexo 4 as médias das covariadas que foram utilizadas para realizar o pareamento. O pareamento foi estimado em cada unidade da federação separadamente uma vez que a oferta de planos de saúde é determinada espacialmente. A análise das tabelas $\mathrm{V}$ a VIII mostra que o matching torna os dois grupos, tratamento e comparação, mais próximos para $70 \%$ das variáveis utilizadas: das 31 variáveis utilizadas, no máximo 9 não apresentam médias estatisticamente iguais entre os dois grupos. O ajustamento do matching é similar tanto para a amostra de todos os indivíduos quanto quando restringimos o grupo de tratamento aos indivíduos que têm plano de assistência de servidor público. A análise das médias das covariadas que ainda apresentaram valores estatisticamente diferentes após o pareamento indica que embora tenha ocorrido uma redução significativa dessas médias, o grupo dos indivíduos com plano de saúde apresenta condição socioeconômica um pouco superior com proporções de indivíduos nos decis de renda extremos diferenciadas. Em relação aos atributos de risco, os dois grupos se distinguem apenas em relação à composição dos domicílios: os domicílios onde residem indivíduos com plano de saúde têm maior presença de criança e de idosos.

\section{RESULTADOS}

Nessa seção, apresentamos os resultados obtidos utilizando os três procedimentos propostos para corrigir a endogeneidade entre a escolha de ter plano de saúde e a utilização de serviços de saúde. Primeiro, analisamos o diferencial de utilização estimado para os indivíduos que têm plano de saúde supondo que esses indivíduos não 
possuem plano privado. Essa é uma estimativa mais ampla do diferencial uma vez que considera toda a população com plano e não um grupo restrito como o PIASP. Discutimos essa estimativa contrafactual para os procedimentos l e 2. Em seguida, discutimos os resultados para o diferencial de utilização estimado para os indivíduos que têm plano de Instituição de Assistência de Servidor público supondo que esses indivíduos não possuem plano de saúde.

\subsection{O Diferencial é Positivo?}

De maneira geral, independente do tipo de procedimento adotado para corrigir o viés de endogeneidade, os resultados indicam que existe diferencial positivo na utilização tanto no cuidado hospitalar quanto no ambulatorial, sugerindo a presença de risco moral no sistema de saúde brasileiro. As Tabelas 5 e 6 reportam os resultados quando estamos analisando a utilização dos serviços de saúde comparando o valor estimado para os indivíduos que possuem plano privado ao contrafactual estimado para esses indivíduos caso não possuíssem plano de saúde. A Tabela 5 reporta os resultados para as estimações realizadas considerando a correção de Heckman, e a Tabela 6 corrige o problema da endogeneidade através do matching. No caso de consultas médicas a magnitude desse diferencial é elevada, cerca de $25 \%$, e esse diferencial é estatisticamente diferente de zero a $1 \%$ para os dois anos. No caso de número de dias internado, a magnitude do diferencial é inferior à encontrada para consultas médicas, situando-se no intervalo de 8 a $15 \%$.

Uma hipótese para explicar essa diferença de magnitude no número médio de dias internado em relação às consultas médicas pode ser a motivação para a realização desse tipo de cuidado. Esses dois tipos de cuidado são bastante diferenciados. A decisão de realizar uma consulta médica, em geral, é motivada por uma demanda de cuidado preventivo, enquanto a demanda de internação é caracterizada como uma demanda por cuidado curativo. $\mathrm{O}$ cuidado preventivo ocorre $e x$-ante à realização da incerteza e, nesse sentido, deve ser mais sensível às condiçóes de acesso. $\mathrm{O}$ cuidado curativo ocorre ex-post à realização da incerteza e nesse sentido é menos elástico a preço e mais relacionado aos atributos de risco.

As estimativas de diferencial de utilização tanto para consultas médicas como para cuidado hospitalar estão em consonância com a evidência empírica internacional. A literatura empírica, embora não apresente um consenso definitivo sobre a magnitude do risco moral, tem evidências suficientes acerca da diferença de sensibilidade entre os tipos de cuidados médicos. Os serviços hospitalares são menos sensíveis a mudanças na divisão de custos, evidenciando menor patamar de risco moral. As 
magnitudes estimadas são muito diversas dependendo do desenho do experimento (ZWEFEL; MANNING, 2000).

TABELA 5 - NÚMERO MÉDIO DE CONSULTAS NO ANO E NÚMERO MÉDIO DE DIAS INTERNADO NOS ÚLTIMOS 12 MESES ESTIMADOS SEGUNDO MÉTODO CONTRAFACTUAL COM CORREÇÃO DE HECKMAN - ANOS 1998 E 2003

\begin{tabular}{clcccc}
\hline \multirow{2}{*}{ Ano } & Variável de utilização & Estimado & Contrafactual & Diferença & Percentual \\
\hline \multirow{2}{*}{1998} & Consultas médicas & 3,15 & 2,39 & 0,80 & $24,1 \%^{* * *}$ \\
& Internação & 0,53 & 0,45 & 0,08 & $15,1 \%^{* * *}$ \\
\hline \multirow{2}{*}{2003} & Consultas médicas & 3,61 & 2,78 & 0,85 & $23,0 \%^{* * *}$ \\
& Internação & 0,50 & 0,44 & 0,06 & $12,0 \%^{* * *}$ \\
\hline
\end{tabular}

Nota: ${ }^{* *}$ médias estatisticamente diferentes a $1 \%$.

TABELA 6 - NÚMERO MÉDIO DE CONSULTAS NO ANO E NÚMERO MÉDIO DE DIAS INTERNADO NOS ÚLTIMOS 12 MESES ESTIMADOS SEGUNDO MÉTODO CONTRAFACTUAL COM PAREAMENTO - ANOS 1998 E 2003

\begin{tabular}{clcccc}
\hline \multirow{2}{*}{ Ano } & Variável de utilização & Estimado & Contrafactual & Diferença & Percentual \\
\hline \multirow{2}{*}{1998} & Consultas médicas & 3,15 & 2,36 & 0,52 & $25 \%^{* * *}$ \\
& Internação & 0,53 & 0,48 & 0,05 & $9,4 \%^{* * *}$ \\
\hline \multirow{2}{*}{2003} & Consultas médicas & 3,61 & 2,62 & 0,99 & $27,4 \%^{* * *}$ \\
& Internação & 0,50 & 0,46 & 0,04 & $8 \%$ \\
\hline
\end{tabular}

Nota: ${ }^{* *}$ médias estatisticamente diferentes a $1 \%$.

\subsection{Os Diferenciais de Utilização entre os Beneficiários do Plano de Instituição de} Assistência de Servidor Público e os Beneficiários do SUS

A Tabela 7 reporta os diferenciais de utilização entre os beneficiários do PIASP e os beneficiários do SUS para os anos de 1998 e 2003. Os resultados evidenciam mais uma vez a presença de risco moral no setor privado de plano de saúde. Nesse caso, a abordagem empírica soluciona o problema da endogeneidade a partir da hipótese de que a decisão de emprego não está relacionada à presença do benefício de plano de saúde. Em geral, no Brasil, a escolha de ser servidor público é motivada pela estabilidade do vínculo empregatício. Para estimar o contrafactual, realizamos primeira- 
mente o pareamento utilizando o método do vizinho mais próximo (NN-Match) e em seguida estimamos o número de dias internado nos últimos 12 meses.

Comparando com os resultados anteriores, notamos que o diferencial de número de consultas médicas continua positivo e estatisticamente significativo. Para essa população, a magnitude do diferencial é um pouco menor em relação à população total que possui plano de saúde, variando de 18 a 20\%, dependendo do ano analisado.

Em relação ao número médio de dias internado no ano, os resultados são bastante diferentes entre os dois anos analisados: em 1998 o diferencial é de quase 16\% e em 2003 essa diferença não é estatisticamente significativa. A comparação entre os dois anos não é simples uma vez que ocorreram mudanças institucionais relevantes no sistema de saúde brasileiro, tanto no setor público, que expandiu bastante sua capacidade de atendimento, como no setor privado, que teve todo o aparato regulatório implementado nesse período.

\section{TABELA 7 - NÚMERO MÉDIO DE CONSULTAS NO ANO E NÚMERO MÉDIO DE DIAS INTERNADO NOS ÚLTIMOS 12 MESES ESTIMADOS SEGUNDO MÉTODO CONTRAFACTUAL COM PAREAMENTO - ANOS 1998 E 2003 - PLANO DE INSTITUIÇÃO DE ASSISTÊNCIA DE SERVIDOR PÚBLICO VERSUS SUS}

\begin{tabular}{rlcccc}
\hline \multirow{2}{*}{ Ano } & Variável de utilização & Estimado & Contrafactual & Diferença & Percentual \\
\hline \multirow{2}{*}{1998} & Consultas médicas & 2,76 & 2,27 & 0,49 & $17,75 \%^{* * *}$ \\
& Internação & 0,63 & 0,53 & 0,10 & $15,87 \%^{* * *}$ \\
\hline \multirow{2}{*}{2003} & Consultas médicas & 3,34 & 2,66 & 0,68 & $20,3 \%^{* * *}$ \\
& Internação & 0,63 & 0,63 & 0 & $0^{\dagger}$ \\
\hline
\end{tabular}

Nota: ${ }^{* * *}$ médias estatisticamente diferentes a $1 \%$.

$\dagger$ médias estatisticamente iguais.

\section{CONSIDERAÇOEES FINAIS}

A contribuição deste trabalho está em investigar a presença de diferenciais de utilização dos serviços de saúde no sistema brasileiro. Para controlar a endogeneidade presente entre as decisões de ter plano de saúde e de utilização dos serviços de saúde propomos três procedimentos. As variáveis de cuidado de saúde analisadas foram o número de consultas médicas e o número de dias internado nos últimos 12 meses. Os resultados encontrados indicam que existe sobreutilização para ambos os tipos 
de cuidado, mas esse diferencial é distinto, dependendo do tipo de cuidado. No caso do cuidado ambulatorial, o diferencial deve estar mais associado ao comportamento do paciente, que é quem decide sobre a realização do cuidado. No caso do cuidado hospitalar, esse diferencial pode estar associado ao comportamento dos provedores, através da indução de demanda, dado que esse cuidado depende, sobretudo, da decisão do médico. Uma extensão desse trabalho seria tentar controlar as características dos provedores a fim de qualificar o tipo de incentivo que pode estar induzindo uma maior utilização. ${ }^{14}$

O risco moral pode comprometer a eficiência dos contratos de plano ou seguro de saúde, gerando perdas de bem-estar, na medida em que os preços praticados se estabelecem acima do nível ótimo. Desse modo, uma das implicações da presença de risco moral mais importantes é que o nível de cobertura da população se estabelece abaixo do nível ótimo. Nem todos os indivíduos que desejam comprar plano ou seguro de saúde vão realizar essa compra. Uma das formas usuais de inibir o risco moral é a implementação de instrumentos monetários e não-monetários de contenção de demanda.

Detectar a presença de risco moral no sistema de saúde brasileiro é importante na medida em que o Brasil é um país em desenvolvimento com restrições na sua capacidade de financiamento e provimento dos bens e serviços considerados meritórios. Além disso, a sustentabilidade de um sistema público de saúde universal e integral conforme previsto na legislação do SUS pode ser pouco viável, sobretudo considerando as inovações tecnológicas contínuas na área da saúde. O setor privado é certamente uma opção para viabilizar o acesso aos serviços de saúde para parte da população brasileira, e a atuação conjunta entre os setores público e privado está proposta desde a concepção do SUS em 1988. Estudos como esse, que de alguma forma se propõem a analisar a adequação dos contratos no setor privado, podem oferecer subsídios para a decisão de políticas de gestão que visem à ampliação da parcela da população com cobertura de plano de saúde.

\section{REFERENNCIAS}

ABADIE, A.; IMBENS, G. Large sample properties of matching estimators for average treatment effects. Econometrica, 74 (1), p. 235-267, 2006.

ANS - Agência Nacional de Saúde Suplementar. Disponível em: http://www.ans. gov.br.

14 No questionário da PNAD não existem informações sobre os provedores dos serviços médicos. 
BARROS, P. P.; MACHADO, M. P.; SANZ-DE-GALDEANO, A. Moral hazard and the demand for health services: a matching estimator approach. Journal of Health Economics, 2007, doi:10.1016/j.jhealeco.2008.02.007

CAMERON, A. C. et al. A microeconomic model of the demand for health care and health insurance in Australia. Review of Economic Studies. v. 55, n. 1, p. 85-106, 1988.

CHIAPPORI, Pierre-André et al. Moral hazard and the demand for physician services: First lessons from a French natural experiment. European Economic Review, n. 42, p 499-511, 1998.

CUTLER, D. M.; ZECKHAUSER, R. J. The anatomy of health insurance. In: CULYER, A. J.; NEWHOUSE, J.P. (Org.). Handbook of health economics. Amsterdam: North-Holland Press, 2000. p. 563-643.

JONES, Andrew. Applied econometrics for health economists - a practical guide. Office of Health Economics, London, 2001.

MANNING, W. G. et al. Health insurance and the demand for medical care: evidence from a randomized experiment. American Economic Review, 77 (3), p. 251-277, 1987.

NEWHOUSE, Joseph P. et al. Free for all? Lessons from the RAND health insurance experiment. Cambridge, MA: Harvard University, 1993.

NORONHA, K V. M. S.; ANDRADE, M. V. Desigualdades sociais em saúde: evidências empíricas sobre o caso brasileiro. Revista Econômica do Nordeste, Fortaleza, v. 32, p. 877-897, 2001.

NYMAN, J. A. The value of health insurance: the access motive. Journal of Health Economics 18, p.141-152, 1999.

PAULY, M. V.; HELD, P. J. Benign moral hazard and the cost-effectiveness analysis of insurance coverage. Journal of Health Economics 9, p. 447-461, 1990.

SAPELLI, C.; VIAL, B. Self-selection end moral hazard in Chilean health insurance. Journal of Health Economics 830, p.1-18, 2003.

SAVAGE, E.; WRIGHT, D. J. Moral hazard and adverse selection in Australian private hospitals. Journal of Health Economics 826, p.1-29, 2002.

STANCIOLI, A. E. Incentivos e risco moral nos planos de sauide no Brasil. 2002. Dissertação (Mestrado em Economia). Orientador: Hélio Zylberstajn. Faculdade de Economia, Administração e Contabilidade da USP, 81 p.

ZWEIFEL, P.; MANNING, Willard G. Moral hazard and consumer incentives in health care. In: CULYER, A. J., NEWHOUSE, J.P. (Org.). Handbook of health economics. Amsterdam: North-Holland Press, 2000. p. 410-459. 


\section{ANEXO 1 - RESULTADOS DOS MODELOS ESTIMADOS DE ACORDO COM O PROCEDIMENTO 1}

\section{TABELA I - COEFICIENTES ESTIMADOS PARA O MODELO DE PROBABI- LIDADE DE TER PLANO DE SAÚDE}

\begin{tabular}{|c|c|c|c|c|c|}
\hline & 1998 & 2003 & & 1998 & 2003 \\
\hline 18 a 29 anos & $-0.168^{\star \star \star}$ & $-0.145^{\star \star \star}$ & Paraíba & $-0.158^{\star \star \star}$ & $-0.297^{\star \star \star}$ \\
\hline 30 a 39 anos & $-0.048^{\star \star \star}$ & $-0.065^{\star \star \star}$ & Pernambuco & $-0.050^{*}$ & $-0.103^{\star \star \star}$ \\
\hline 40 a 49 anos & $-0.027^{\star \star \star}$ & $-0.068^{\star \star \star}$ & Alagoas & $-0.348^{\star \star \star}$ & $-0.444^{\star \star \star}$ \\
\hline 50 a 59 anos & $0.064^{* \star *}$ & $0.023^{*}$ & Sergipe & $-0.216^{\star \star \star}$ & $-0.426^{\star \star \star}$ \\
\hline 60 a 69 anos & $0.137^{\star * *}$ & $0.081^{* * *}$ & Bahia & $-0.187^{* \star *}$ & $-0.138^{\star \star \star}$ \\
\hline Mais de 70 anos & $0.058^{* *}$ & $0.107^{\star \star *}$ & Minas Gerais & $-0.049^{\star *}$ & $-0.036^{*}$ \\
\hline Presença de criança na família & $0.137^{\star \star *}$ & $0.157^{\star \star *}$ & Espírito Santo & $-0.099^{* *}$ & $-0.101^{* \star \star}$ \\
\hline Presença de idoso na família & $-0.091^{\star * \star}$ & $-0.048^{\star *}$ & Rio de Janeiro & $-0.197^{\star \star \star}$ & $-0.318^{\star \star \star}$ \\
\hline $\begin{array}{l}\text { Presença de mulher em idade fértil na } \\
\text { família }\end{array}$ & $0.165^{\star \star \star}$ & $0.183^{\star \star \star}$ & Paraná & $-0.319^{\star \star \star}$ & $-0.294^{\star \star \star}$ \\
\hline $1^{\circ}$. Dec de rfpc & $-2.053^{* \star \star}$ & $-2.025^{\star * \star}$ & Santa Catarina & $-0.364^{\star \star *}$ & $-0.342^{* \star *}$ \\
\hline $2^{\circ}$. Dec de rfpc & $-1.935^{* \star *}$ & $-2.011^{1 * *}$ & Rio Grande do Sul & $-0.104^{* * *}$ & $-0.071^{\star \star \star}$ \\
\hline 3․ Dec de rfpc & $-1.737^{* * *}$ & $-1.824^{* \star *}$ & Mato Grosso do Sul & $-0.088^{\star *}$ & $0.125^{\star \star \star}$ \\
\hline $4^{\circ}$. Dec de rfpc & $-1.578^{\star \star \star}$ & $-1.594^{* \star \star}$ & Mato Grosso & $-0.607^{\star \star \star}$ & $-0.384^{\star \star \star}$ \\
\hline $5^{\circ}$. Dec de rfpc & $-1.369^{* \star \star}$ & $-1.449^{* \star \star}$ & Goiás & $-0.107^{\star \star \star}$ & $-0.118^{\star \star \star}$ \\
\hline 6. Dec de rfpc & $-1.219^{\star \star \star}$ & $-1.242^{\star \star \star}$ & Distrito Federal & $-0.430^{\star \star \star}$ & $-0.438^{\star \star \star}$ \\
\hline $7^{\circ}$. Dec de rfpc & $-0.997^{\star \star \star}$ & $-1.005^{\star \star \star}$ & até 3 anos de estudo & $-1.016^{\star \star \star}$ & $-1.037^{\star \star \star}$ \\
\hline 8․ Dec de rfpc & $-0.790^{* * *}$ & $-0.805^{* * *}$ & 4 a 7 anos de estudo & $-0.733^{\star * *}$ & $-0.803^{* \star *}$ \\
\hline $9^{\circ}$. Dec de rfpc & $-0.466^{* \star \star}$ & $-0.499^{* \star *}$ & 8 a 10 anos de estudo & $-0.485^{\star \star \star}$ & $-0.571^{* \star \star}$ \\
\hline Chefe em emprego Sem carteira & $-0.684^{* * *}$ & $-0.583^{* \star *}$ & 11 a 14 anos de estudo & $-0.268^{* * *}$ & $-0.292^{* \star \star}$ \\
\hline Chefe em emprego Doméstico & $-0.672^{* \star \star}$ & $-0.613^{\star \star \star}$ & Metropolitana & $0.271^{\star \star \star}$ & $0.256^{\star \star \star}$ \\
\hline Chefe em emprego Conta Própria & $-0.719^{* \star *}$ & $-0.608^{* \star \star}$ & Núm. de compon. da fam. & 0.004 & 0.005 \\
\hline Chefe Empregador & $-0.569^{* \star \star}$ & $-0.440^{\star \star \star}$ & $\%$ na fam. coluna & 0.015 & $0.202^{\star \star \star}$ \\
\hline Chefe em emprego Não Remunerado & $-0.312^{\star \star \star}$ & $-0.246^{\star \star \star}$ & \% na fam. câncer & 0.051 & 0.071 \\
\hline Chefe Não PEA & $-0.260^{* * \star}$ & $-0.250^{* * *}$ & $\%$ na fam. diabetes & 0.007 & 0.029 \\
\hline Chefe Desocupado & $-0.260^{* * \star}$ & $-0.274^{* \star *}$ & $\%$ na fam. asma & $0.138^{\star \star *}$ & $0.172^{* \star *}$ \\
\hline $\begin{array}{l}\text { Chefe em emprego Militar ou Funcionário } \\
\text { Público }\end{array}$ & $0.301^{* * *}$ & $0.196^{* \star *}$ & $\%$ na fam. hiperten & 0.034 & 0.022 \\
\hline Rondônia & $-0.354^{* * \star}$ & $-0.368^{* \star *}$ & \% na fam. coração & $0.099^{* *}$ & $0.106^{* \star \star}$ \\
\hline Acre & $-0.936^{* * \star}$ & $-0.409^{* * *}$ & $\%$ na fam. renal & $-0.163^{\star \star *}$ & $-0.100^{*}$ \\
\hline Amazonas & $-0.375^{\star \star \star}$ & $-0.544^{* \star \star}$ & $\%$ na fam. depres & -0.023 & $0.060^{*}$ \\
\hline Roraima & $-1.479^{\star \star \star}$ & $-0.837^{\star \star \star}$ & $\%$ na fam. tuberc & $-0.890^{\star \star}$ & -0.036 \\
\hline Pará & -0.046 & $-0.195^{\star \star \star}$ & $\%$ na fam. tendinite & $0.430^{\star \star \star}$ & $0.484^{\star \star \star}$ \\
\hline Amapá & $-0.465^{\star \star \star}$ & $-0.545^{\star \star \star}$ & $\%$ na fam. cirrose & $0.397^{\star}$ & 0.177 \\
\hline Tocantins & $-0.300^{* \star \star}$ & $-0.822^{\star \star \star}$ & $\begin{array}{l}\text { \% na fam. saúde } \\
\text { autoavaliada boa }\end{array}$ & $0.000^{* *}$ & $0.002^{* * \star}$ \\
\hline Maranhão & $-0.564^{* * *}$ & $-0.597^{* * \star}$ & Idade do chefe & $0.005^{* * *}$ & $0.006^{\star \star \star}$ \\
\hline Piauí & $-0.342^{* \star \star}$ & $-0.262^{* \star \star}$ & Sexo & $-0.092^{\star \star *}$ & $-0.083^{* * *}$ \\
\hline Ceará & $-0.286^{* \star \star}$ & $-0.238^{\star \star \star}$ & Constante & $0.823^{\star \star \star}$ & $0.605^{\star \star \star}$ \\
\hline Rio Grande do Norte & $-0.510^{* \star *}$ & $-0.518^{\star \star \star}$ & & & \\
\hline
\end{tabular}


TABELA II - COEFICIENTES ESTIMADOS PARA O MODELO DE UTILIZAÇÃO DE CONSULTAS MÉDICAS E INTERNAÇÃO - TODOS OS PLANOS

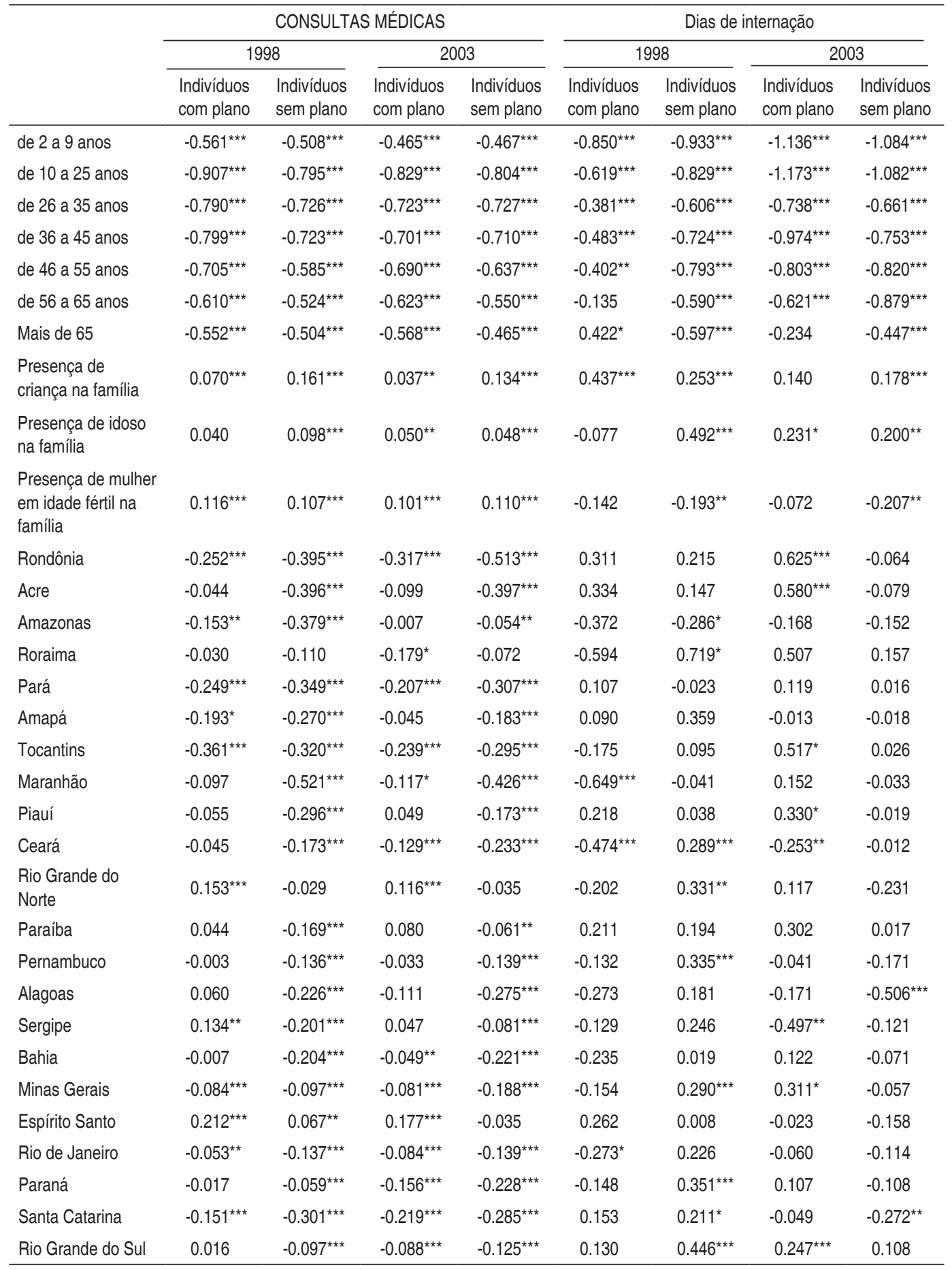




\begin{tabular}{|c|c|c|c|c|c|c|c|c|}
\hline & \multicolumn{4}{|c|}{ CONSULTAS MÉDICAS } & \multicolumn{4}{|c|}{ Dias de internação } \\
\hline & \multicolumn{2}{|c|}{1998} & \multicolumn{2}{|c|}{2003} & \multicolumn{2}{|c|}{1998} & \multicolumn{2}{|c|}{2003} \\
\hline & $\begin{array}{l}\text { Indivíduos } \\
\text { com plano }\end{array}$ & $\begin{array}{l}\text { Indivíduos } \\
\text { sem plano }\end{array}$ & $\begin{array}{l}\text { Indivíduos } \\
\text { com plano }\end{array}$ & $\begin{array}{l}\text { Indivíduos } \\
\text { sem plano }\end{array}$ & $\begin{array}{l}\text { Indivíduos } \\
\text { com plano }\end{array}$ & $\begin{array}{l}\text { Indivíduos } \\
\text { sem plano }\end{array}$ & $\begin{array}{l}\text { Indivíduos } \\
\text { com plano }\end{array}$ & $\begin{array}{l}\text { Indivíduos } \\
\text { sem plano }\end{array}$ \\
\hline Mato Grosso do Sul & -0.040 & $-0.056^{*}$ & $-0.109^{\star \star \star}$ & $-0.130^{\star * *}$ & 0.186 & $0.231^{*}$ & 0.068 & 0.029 \\
\hline Mato Grosso & $-0.170^{\star *}$ & $-0.394^{\star \star \star}$ & $-0.276^{\star \star \star}$ & $-0.205^{\star * *}$ & $0.320^{*}$ & 0.080 & $0.465^{\star \star \star}$ & -0.031 \\
\hline Goiás & $-0.158^{* * \star}$ & $-0.190^{\star \star \star}$ & $-0.208^{\star \star \star}$ & $-0.217^{\star \star *}$ & 0.071 & $0.288^{\star \star \star}$ & $0.410^{* *}$ & 0.085 \\
\hline Distrito Federal & 0.026 & $-0.115^{\star \star \star}$ & $-0.131^{\star \star \star}$ & $-0.302^{\star \star \star}$ & -0.106 & 0.026 & $-0.260^{*}$ & 0.037 \\
\hline $\begin{array}{l}\text { Região } \\
\text { metropolitana }\end{array}$ & $0.258^{* \star \star}$ & $0.306^{* \star *}$ & $0.299^{* \star *}$ & $0.277^{\star \star \star}$ & 0.015 & 0.056 & -0.019 & -0.053 \\
\hline Região urbana & 0.047 & $0.131^{\star \star \star}$ & $0.147^{\star \star \star}$ & $0.172^{\star \star \star}$ & -0.070 & $0.111^{\star *}$ & $-0.225^{\star \star}$ & 0.035 \\
\hline $\begin{array}{l}\text { Número de } \\
\text { componentes na } \\
\text { família }\end{array}$ & $-0.063^{\star \star \star}$ & $-0.068^{\star * *}$ & $-0.046^{* * *}$ & $-0.060^{* * *}$ & -0.054 & $-0.066^{\star \star \star}$ & 0.040 & -0.025 \\
\hline Coluna & $0.172^{* * *}$ & $0.202^{* \star *}$ & $0.193^{* \star \star}$ & $0.211^{\star \star *}$ & 0.044 & $-0.131^{* * *}$ & 0.028 & -0.052 \\
\hline Artrite & $0.043^{* \star}$ & $0.070^{* * *}$ & $0.063^{* \star \star}$ & $0.086^{\star \star \star}$ & $-0.169^{*}$ & $-0.129^{* *}$ & 0.138 & -0.024 \\
\hline Câncer & $0.596^{* \star \star}$ & $0.811^{\star \star \star}$ & $0.531^{\star \star \star}$ & $0.568^{\star \star \star}$ & $1.618^{\star \star \star}$ & $1.385^{\star \star \star}$ & $1.218^{\star \star \star}$ & $1.207^{\star \star \star}$ \\
\hline Diabetes & $0.318^{* \star \star}$ & $0.381^{* \star *}$ & $0.245^{\star \star \star}$ & $0.353^{\star \star *}$ & $0.585^{\star \star \star}$ & $0.535^{\star \star \star}$ & 0.157 & $0.503^{* \star *}$ \\
\hline Asma & $0.364^{\star \star \star}$ & $0.441^{\star \star \star}$ & $0.245^{\star \star \star}$ & $0.320^{\star \star *}$ & $0.702^{\star \star \star}$ & $0.512^{\star \star \star}$ & $0.461^{\star \star \star}$ & $0.571^{\star \star *}$ \\
\hline Hipertensão & $0.220^{* \star *}$ & $0.332^{* * *}$ & $0.200^{* \star *}$ & $0.368^{* * *}$ & 0.127 & $0.093^{*}$ & 0.135 & $0.162^{* * *}$ \\
\hline Coração & $0.192^{\star \star \star}$ & $0.280^{* * *}$ & $0.197^{\star \star \star}$ & $0.238^{* * *}$ & $0.796^{* * *}$ & $0.543^{\star \star *}$ & $0.650^{\star \star \star}$ & $0.623^{\star * *}$ \\
\hline Renal & $0.190^{* \star *}$ & $0.110^{* * *}$ & $0.194^{* \star \star}$ & $0.146^{* * *}$ & $0.589^{* * *}$ & $0.504^{\star * *}$ & $0.801^{* * *}$ & $0.441^{* * *}$ \\
\hline Depressão & $0.292^{* \star *}$ & $0.265^{\star \star \star}$ & $0.286^{\star \star \star}$ & $0.312^{\star \star \star}$ & $0.471^{* \star *}$ & $0.780^{\star \star \star}$ & $0.669^{* * *}$ & $0.755^{\star \star \star}$ \\
\hline Tuberculose & $0.450^{\star \star}$ & $0.550^{\star \star \star}$ & $0.274^{* *}$ & $0.410^{\star \star *}$ & $1.208^{* \star}$ & $1.212^{\star \star \star}$ & 0.905 & $1.576^{\star \star \star}$ \\
\hline Tendinite & $0.204^{\star \star \star}$ & $0.172^{\star \star \star}$ & $0.189^{* \star \star}$ & $0.132^{\star \star *}$ & -0.007 & 0.015 & -0.091 & $-0.417^{\star \star \star}$ \\
\hline Cirrose & $0.284^{\star \star}$ & $0.226^{\star \star \star}$ & 0.152 & $0.294^{\star \star *}$ & $1.146^{\star \star *}$ & $1.225^{\star \star \star}$ & $0.530^{*}$ & $1.278^{\star \star \star}$ \\
\hline Saúde autoavaliada & $-0.463^{\star * *}$ & $-0.707^{\star \star *}$ & $-0.432^{* * *}$ & $-0.608^{* * *}$ & $-0.973^{\star * *}$ & $-1.321^{* * *}$ & $-1.040^{* * *}$ & $-1.113^{* * *}$ \\
\hline $\begin{array}{l}\text { Idade do chefe de } \\
\text { família }\end{array}$ & $-0.007^{* * *}$ & $-0.008^{* \star \star}$ & $-0.006^{\star \star \star}$ & $-0.006^{* * *}$ & $-0.010^{* *}$ & $-0.016^{* \star *}$ & $-0.012^{* * *}$ & $-0.014^{\star \star \star}$ \\
\hline Sexo & $-0.329^{\star \star \star}$ & $-0.413^{\star \star \star}$ & $-0.322^{* \star \star}$ & $-0.414^{* \star *}$ & $-0.142^{\star *}$ & $-0.186^{\star \star \star}$ & $-0.142^{* *}$ & 0.024 \\
\hline $\begin{array}{l}\text { Até } 3 \text { anos de } \\
\text { estudo }\end{array}$ & $-0.166^{\star \star \star}$ & $-0.087^{\star \star}$ & $-0.179^{\star \star \star}$ & -0.036 & 0.021 & $0.680^{\star \star \star}$ & $0.174^{*}$ & $0.392^{*}$ \\
\hline $\begin{array}{l}\text { De } 4 \text { a } 7 \text { anos de } \\
\text { estudo }\end{array}$ & $-0.144^{\star * *}$ & 0.009 & $-0.157^{\star \star \star}$ & 0.010 & 0.057 & $0.646^{\star \star \star}$ & $0.220^{* *}$ & $0.384^{*}$ \\
\hline $\begin{array}{l}\text { De } 8 \text { a } 10 \text { anos } \\
\text { de est. }\end{array}$ & $-0.103^{\star \star *}$ & 0.035 & $-0.087^{* \star \star}$ & 0.033 & 0.229 & $0.466^{\star \star \star}$ & $0.219^{\star \star}$ & $0.540^{\star *}$ \\
\hline $\begin{array}{l}\text { De } 11 \text { a } 14 \text { anos } \\
\text { de est. }\end{array}$ & $-0.076^{\star \star \star}$ & $0.068^{\star}$ & $-0.055^{\star * \star}$ & $0.051^{*}$ & -0.092 & $0.401^{* *}$ & $0.265^{\star \star \star}$ & 0.374 \\
\hline Qualidade & $0.369^{\star \star \star}$ & $0.527^{\star \star *}$ & $0.353^{* \star \star}$ & $0.474^{* \star *}$ & $0.440^{* \star *}$ & $0.535^{\star \star *}$ & $0.372^{\star \star *}$ & $0.470^{\star \star *}$ \\
\hline Acesso & $0.126^{\star * \star}$ & $0.114^{* \star *}$ & $0.181^{* * \star}$ & $0.078^{\star \star *}$ & $0.358^{*}$ & $0.373^{\star \star \star}$ & $0.324^{\star \star}$ & $0.426^{\star * *}$ \\
\hline Constante & $2.327^{\star \star \star}$ & $1.873^{* * *}$ & $2.280^{* \star \star}$ & $1.915^{\star \star \star}$ & 0.413 & 0.335 & $0.517^{\star}$ & $0.534^{\star}$ \\
\hline
\end{tabular}

Nota: ${ }^{*}$ significativo a $10 \%$; ${ }^{*}$ significativo a $5 \%$; ${ }^{* *}$ significativo a $1 \%$. 
ANEXO 2- RESULTADOS DOS MODELOS ESTIMADOS DE ACORDO COM O PROCEDIMENTO 2 (MÉTODO DO MATCHING)

TABELA III - COEFICIENTES ESTIMADOS PARA O MODELO DE UTILIZAÇÃO DE CONSULTAS MÉDICAS E INTERNAÇÃO - TODOS OS PLANOS

\begin{tabular}{|c|c|c|c|c|c|c|c|c|}
\hline & \multicolumn{4}{|c|}{ CONSULTAS MÉDICAS } & \multicolumn{4}{|c|}{ Dias de internação } \\
\hline & \multicolumn{2}{|c|}{1998} & \multicolumn{2}{|c|}{2003} & \multicolumn{2}{|c|}{1998} & \multicolumn{2}{|c|}{2003} \\
\hline & $\begin{array}{l}\text { Indivíduos } \\
\text { com plano }\end{array}$ & $\begin{array}{l}\text { Indivíduos } \\
\text { sem plano }\end{array}$ & $\begin{array}{l}\text { Indivíduos } \\
\text { com plano }\end{array}$ & $\begin{array}{l}\text { Indivíduos } \\
\text { sem plano }\end{array}$ & $\begin{array}{l}\text { Indivíduos } \\
\text { com plano }\end{array}$ & $\begin{array}{l}\text { Indivíduos } \\
\text { sem plano }\end{array}$ & $\begin{array}{l}\text { Indivíduos } \\
\text { com plano }\end{array}$ & $\begin{array}{l}\text { Indivíduos } \\
\text { sem plano }\end{array}$ \\
\hline de 2 a 9 anos & $-0.561^{* * *}$ & $-0.660^{* * *}$ & $-0.465^{\star \star \star}$ & $-0.465^{* * *}$ & $-0.850^{* * *}$ & $-0.848^{* * *}$ & $-1.136^{\star * \star}$ & $-1.013^{* \star *}$ \\
\hline de 10 a 25 anos & $-0.907^{\star * *}$ & $-1.082^{\star \star \star}$ & $-0.829^{\star \star \star}$ & $-0.829^{\star * \star}$ & $-0.619^{* * *}$ & $-0.584^{* * *}$ & $-1.173^{\star \star *}$ & $-1.231^{* \star *}$ \\
\hline de 26 a 35 anos & $-0.790^{\star * *}$ & $-0.983^{* \star \star}$ & $-0.723^{\star * \star}$ & $-0.723^{* * *}$ & $-0.381^{* * *}$ & -0.304 & $-0.738^{\star * *}$ & $-0.695^{* * *}$ \\
\hline de 36 a 45 anos & $-0.799^{\star \star *}$ & $-1.004^{\star \star \star}$ & $-0.701^{\star * *}$ & $-0.701^{* * *}$ & $-0.483^{\star \star *}$ & $-0.449^{\star *}$ & $-0.974^{\star * *}$ & $-0.607^{* *}$ \\
\hline de 46 a 55 anos & $-0.705^{\star \star \star}$ & $-0.903^{\star \star *}$ & $-0.690^{\star * *}$ & $-0.690^{\star * \star}$ & $-0.402^{\star *}$ & -0.337 & $-0.803^{\star \star *}$ & $-1.045^{\star \star \star}$ \\
\hline de 56 a 65 anos & $-0.610^{* * *}$ & $-0.781^{\star \star *}$ & $-0.623^{\star \star \star}$ & $-0.623^{\star \star \star}$ & -0.135 & 0.114 & $-0.621^{* * *}$ & $-0.785^{\star \star \star}$ \\
\hline Mais de 65 & $-0.552^{* * *}$ & $-0.782^{* * *}$ & $-0.568^{\star \star \star}$ & $-0.568^{\star \star \star}$ & $0.422^{*}$ & 0.048 & -0.234 & -0.421 \\
\hline $\begin{array}{l}\text { Presença de } \\
\text { criança na família }\end{array}$ & $0.070^{* * *}$ & $0.158^{\star \star \star}$ & $0.037^{\star *}$ & $0.037^{\star \star}$ & $0.437^{* * *}$ & $0.489^{* * *}$ & 0.140 & -0.175 \\
\hline $\begin{array}{l}\text { Presença de idoso } \\
\text { na família }\end{array}$ & 0.040 & 0.082 & $0.050^{\star *}$ & $0.050^{* *}$ & -0.077 & $0.678^{\star \star *}$ & $0.231^{*}$ & 0.076 \\
\hline $\begin{array}{l}\text { Presença de } \\
\text { mulher em idade } \\
\text { fértil na família }\end{array}$ & $0.116^{* * *}$ & 0.031 & $0.101^{* * *}$ & $0.101^{* \star *}$ & -0.142 & -0.034 & -0.072 & 0.128 \\
\hline Rondônia & $-0.252^{* \star *}$ & -0.178 & $-0.317^{\star \star *}$ & $-0.317^{\star * *}$ & 0.311 & 0.463 & $0.625^{* * *}$ & 0.035 \\
\hline Acre & -0.044 & -0.250 & -0.099 & -0.099 & 0.334 & 1.232 & $0.580^{* * *}$ & -0.049 \\
\hline Amazonas & $-0.153^{\star *}$ & $-0.424^{* * *}$ & -0.007 & -0.007 & -0.372 & $-0.740^{* \star *}$ & -0.168 & -0.100 \\
\hline Roraima & -0.030 & 0.221 & $-0.179^{\star}$ & $-0.179^{\star}$ & -0.594 & -0.799 & 0.507 & 0.180 \\
\hline Pará & $-0.249^{* * *}$ & $-0.108^{*}$ & $-0.207^{\star * \star}$ & $-0.207^{\star * *}$ & 0.107 & -0.071 & 0.119 & 0.131 \\
\hline Amapá & $-0.193^{*}$ & -0.158 & -0.045 & -0.045 & 0.090 & 1.017 & -0.013 & 0.850 \\
\hline Tocantins & $-0.361^{* * *}$ & $-0.240^{* *}$ & $-0.239^{\star \star *}$ & $-0.239^{\star * \star}$ & -0.175 & -0.103 & $0.517^{\star}$ & $0.872^{\star *}$ \\
\hline Maranhão & -0.097 & -0.013 & $-0.117^{\star}$ & $-0.117^{\star}$ & $-0.649^{* \star *}$ & -0.248 & 0.152 & 0.419 \\
\hline Piauí & -0.055 & $-0.265^{\star \star \star}$ & 0.049 & 0.049 & 0.218 & -0.114 & $0.330^{*}$ & -0.242 \\
\hline Ceará & -0.045 & $-0.198^{\star \star \star}$ & $-0.129^{\star * *}$ & $-0.129^{\star \star *}$ & $-0.474^{\star \star \star}$ & 0.110 & $-0.253^{* *}$ & 0.323 \\
\hline $\begin{array}{l}\text { Rio Grande do } \\
\text { Norte }\end{array}$ & $0.153^{\star \star \star}$ & -0.053 & $0.116^{\star \star *}$ & $0.116^{\star \star *}$ & -0.202 & 0.014 & 0.117 & 0.346 \\
\hline Paraíba & 0.044 & 0.124 & 0.080 & 0.080 & 0.211 & -0.192 & 0.302 & -0.152 \\
\hline Pernambuco & -0.003 & 0.070 & -0.033 & -0.033 & -0.132 & 0.143 & -0.041 & -0.085 \\
\hline Alagoas & 0.060 & 0.075 & -0.111 & -0.111 & -0.273 & 0.015 & -0.171 & $-0.933^{\star \star \star}$ \\
\hline Sergipe & $0.134^{\star *}$ & 0.061 & 0.047 & 0.047 & -0.129 & 0.405 & $-0.497^{\star \star}$ & $-0.468^{*}$ \\
\hline Bahia & -0.007 & -0.012 & $-0.049^{* *}$ & $-0.049^{* *}$ & -0.235 & -0.130 & 0.122 & -0.047 \\
\hline Minas Gerais & $-0.084^{* \star *}$ & -0.047 & $-0.081^{\star \star *}$ & $-0.081^{* \star *}$ & -0.154 & $0.239^{*}$ & $0.311^{*}$ & 0.146 \\
\hline Espírito Santo & $0.212^{\star \star \star}$ & $0.163^{\star *}$ & $0.177^{\star \star \star}$ & $0.177^{\star \star \star}$ & 0.262 & -0.189 & -0.023 & 0.192 \\
\hline Rio de Janeiro & $-0.053^{\star \star}$ & -0.049 & $-0.084^{\star \star \star}$ & $-0.084^{* \star *}$ & $-0.273^{*}$ & 0.011 & -0.060 & 0.017 \\
\hline
\end{tabular}




\begin{tabular}{|c|c|c|c|c|c|c|c|c|}
\hline & \multicolumn{4}{|c|}{ CONSULTAS MÉDICAS } & \multicolumn{4}{|c|}{ Dias de internação } \\
\hline & \multicolumn{2}{|c|}{1998} & \multicolumn{2}{|c|}{2003} & \multicolumn{2}{|c|}{1998} & \multicolumn{2}{|c|}{2003} \\
\hline & $\begin{array}{l}\text { Indivíduos } \\
\text { com plano }\end{array}$ & $\begin{array}{l}\text { Indivíduos } \\
\text { sem plano }\end{array}$ & $\begin{array}{l}\text { Indivíduos } \\
\text { com plano }\end{array}$ & $\begin{array}{l}\text { Indivíduos } \\
\text { sem plano }\end{array}$ & $\begin{array}{l}\text { Indivíduos } \\
\text { com plano }\end{array}$ & $\begin{array}{l}\text { Indivíduos } \\
\text { sem plano }\end{array}$ & $\begin{array}{l}\text { Indivíduos } \\
\text { com plano }\end{array}$ & $\begin{array}{l}\text { Indivíduos } \\
\text { sem plano }\end{array}$ \\
\hline Paraná & -0.017 & 0.013 & $-0.156^{\star \star \star}$ & $-0.156^{\star * *}$ & -0.148 & 0.201 & 0.107 & -0.136 \\
\hline Santa Catarina & $-0.151^{\star * *}$ & $-0.220^{\star * *}$ & $-0.219^{\star * *}$ & $-0.219^{\star * *}$ & 0.153 & -0.192 & -0.049 & -0.078 \\
\hline Rio Grande do Sul & 0.016 & 0.045 & $-0.088^{\star \star \star}$ & $-0.088^{\star \star *}$ & 0.130 & $0.282^{*}$ & $0.247^{\star \star *}$ & 0.068 \\
\hline $\begin{array}{l}\text { Mato Grosso } \\
\text { do Sul }\end{array}$ & -0.040 & -0.004 & $-0.109^{\star \star \star}$ & $-0.109^{\star \star *}$ & 0.186 & 0.199 & 0.068 & 0.152 \\
\hline Mato Grosso & $-0.170^{\star \star}$ & $-0.198^{\star \star *}$ & $-0.276^{\star \star \star}$ & $-0.276^{\star \star \star}$ & $0.320^{*}$ & -0.078 & $0.465^{\star \star *}$ & 0.135 \\
\hline Goiás & $-0.158^{\star * *}$ & $-0.094^{*}$ & $-0.208^{\star \star *}$ & $-0.208^{\star \star *}$ & 0.071 & 0.076 & $0.410^{* *}$ & 0.312 \\
\hline Distrito Federal & 0.026 & -0.027 & $-0.131^{\star \star *}$ & $-0.131^{\star \star *}$ & -0.106 & -0.065 & $-0.260^{*}$ & -0.109 \\
\hline $\begin{array}{l}\text { Região } \\
\text { metropolitana }\end{array}$ & $0.258^{\star * *}$ & $0.187^{\star \star \star}$ & $0.299^{\star * \star}$ & $0.299^{* * *}$ & 0.015 & -0.248 & -0.019 & $-1.028^{*}$ \\
\hline Região urbana & 0.047 & 0.032 & $0.147^{\star \star \star}$ & $0.147^{\star \star *}$ & -0.070 & -0.087 & $-0.225^{\star \star}$ & $-1.045^{\star}$ \\
\hline $\begin{array}{l}\text { Número de } \\
\text { componentes na } \\
\text { família }\end{array}$ & $-0.063^{\star \star \star}$ & $-0.059^{\star \star \star}$ & $-0.046^{\star \star \star}$ & $-0.046^{\star \star \star}$ & -0.054 & -0.053 & 0.040 & 0.003 \\
\hline Coluna & $0.172^{\star \star *}$ & $0.172^{\star \star \star}$ & $0.193^{\star * \star}$ & $0.193^{\star \star *}$ & 0.044 & -0.177 & 0.028 & $-0.287^{\star *}$ \\
\hline Artrite & $0.043^{\star *}$ & $0.128^{\star \star \star}$ & $0.063^{\star \star \star}$ & $0.063^{\star \star \star}$ & $-0.169^{*}$ & -0.050 & 0.138 & -0.144 \\
\hline Câncer & $0.596^{\star * *}$ & $0.496^{\star * *}$ & $0.531^{\star * *}$ & $0.531^{* \star *}$ & $1.618^{\star \star *}$ & $1.871^{* \star *}$ & $1.218^{* * *}$ & $1.032^{* * *}$ \\
\hline Diabetes & $0.318^{\star * *}$ & $0.292^{* * *}$ & $0.245^{\star \star *}$ & $0.245^{\star \star *}$ & $0.585^{\star \star \star}$ & $0.787^{\star \star *}$ & 0.157 & $0.690^{\star *}$ \\
\hline Asma & $0.364^{\star \star \star}$ & $0.429^{\star * \star}$ & $0.245^{\star \star \star}$ & $0.245^{\star \star *}$ & $0.702^{\star \star *}$ & $0.314^{\star *}$ & $0.461^{* \star *}$ & $0.986^{* * *}$ \\
\hline Hipertensão & $0.220^{* * *}$ & $0.362^{\star * *}$ & $0.200^{\star * *}$ & $0.200^{* \star *}$ & 0.127 & 0.083 & 0.135 & -0.094 \\
\hline Coração & $0.192^{\star \star \star}$ & $0.396^{\star * *}$ & $0.197^{\star \star \star}$ & $0.197^{\star \star \star}$ & $0.796^{\star * *}$ & $0.719^{* \star \star}$ & $0.650^{* \star *}$ & $0.703^{* * *}$ \\
\hline Renal & $0.190^{* * *}$ & $0.170^{\star * \star}$ & $0.194^{\star \star *}$ & $0.194^{* * *}$ & $0.589^{* \star *}$ & $0.917^{* \star *}$ & $0.801^{* * *}$ & $0.415^{\star \star \star}$ \\
\hline Depressão & $0.292^{\star * *}$ & $0.257^{\star \star *}$ & $0.286^{\star * *}$ & $0.286^{* * *}$ & $0.471^{* * *}$ & $0.568^{\star * *}$ & $0.669^{\star * *}$ & $0.796^{* * *}$ \\
\hline Tuberculose & $0.450^{\star *}$ & $0.642^{*}$ & $0.274^{* *}$ & $0.274^{\star *}$ & $1.208^{\star *}$ & 0.344 & 0.905 & 0.642 \\
\hline Tendinite & $0.204^{* * *}$ & $0.207^{\star \star \star}$ & $0.189^{\star \star \star}$ & $0.189^{\star \star \star}$ & -0.007 & 0.164 & -0.091 & $-0.625^{\star \star \star}$ \\
\hline Cirrose & $0.284^{* *}$ & 0.311 & 0.152 & 0.152 & $1.146^{* * *}$ & $1.347^{\star}$ & $0.530^{*}$ & $2.137^{* * *}$ \\
\hline $\begin{array}{l}\text { Saúde } \\
\text { autoavaliada }\end{array}$ & $-0.463^{\star \star \star}$ & $-0.644^{\star \star \star}$ & $-0.432^{\star \star *}$ & $-0.432^{\star \star \star}$ & $-0.973^{\star \star \star}$ & $-1.343^{\star \star *}$ & $-1.040^{\star \star *}$ & $-1.345^{\star * *}$ \\
\hline $\begin{array}{l}\text { Idade do chefe de } \\
\text { família }\end{array}$ & $-0.007^{\star \star *}$ & $-0.007^{\star \star \star}$ & $-0.006^{* \star *}$ & $-0.006^{\star \star *}$ & $-0.010^{\star *}$ & $-0.020^{\star \star \star}$ & $-0.012^{\star \star *}$ & -0.005 \\
\hline Sexo & $-0.329^{\star * *}$ & $-0.365^{\star \star \star}$ & $-0.322^{\star \star \star}$ & $-0.322^{\star \star \star}$ & $-0.142^{\star \star}$ & -0.117 & $-0.142^{* *}$ & -0.012 \\
\hline $\begin{array}{l}\text { até } 3 \text { anos de } \\
\text { estudo }\end{array}$ & $-0.166^{\star \star \star}$ & -0.069 & $-0.179^{\star \star \star}$ & $-0.179^{\star * *}$ & 0.021 & $0.485^{\star \star}$ & $0.174^{*}$ & $0.423^{\star *}$ \\
\hline $\begin{array}{l}\text { de } 4 \text { a } 7 \text { anos de } \\
\text { estudo }\end{array}$ & $-0.144^{\star \star \star}$ & 0.022 & $-0.157^{\star \star \star}$ & $-0.157^{\star \star \star}$ & 0.057 & $0.495^{\star \star}$ & $0.220^{\star \star}$ & $0.659^{\star \star \star}$ \\
\hline $\begin{array}{l}\text { de } 8 \text { a } 10 \text { anos de } \\
\text { estudo }\end{array}$ & $-0.103^{\star \star \star}$ & 0.022 & $-0.087^{\star \star *}$ & $-0.087^{\star \star \star}$ & 0.229 & $0.441^{* \star}$ & $0.219^{\star *}$ & $0.698^{* * *}$ \\
\hline $\begin{array}{l}\text { de } 11 \text { a } 14 \text { anos } \\
\text { de estudo }\end{array}$ & $-0.076^{\star \star *}$ & -0.011 & $-0.055^{\star \star *}$ & $-0.055^{\star \star *}$ & -0.092 & -0.039 & $0.265^{\star \star *}$ & $0.767^{\star \star \star}$ \\
\hline Qualidade & $0.369^{\star \star *}$ & $0.521^{\star \star *}$ & $0.353^{* \star *}$ & $0.353^{* * *}$ & $0.440^{* * *}$ & $0.661^{* \star *}$ & $0.372^{* \star *}$ & $0.461^{* * *}$ \\
\hline Acesso & $0.126^{\star \star *}$ & $0.151^{\star *}$ & $0.181^{* * *}$ & $0.181^{* * *}$ & $0.358^{*}$ & 0.230 & $0.324^{* *}$ & -0.032 \\
\hline Constante & $2.327^{\star \star \star}$ & $2.119^{\star \star \star}$ & $2.280^{\star \star \star}$ & $2.280^{\star * \star}$ & 0.413 & 0.113 & $0.517^{*}$ & 0.849 \\
\hline
\end{tabular}

Nota: ${ }^{*}$ significativo a $10 \% ;{ }^{*}$ significativo a $5 \%$; ${ }^{* *}$ significativo a $1 \%$. 


\section{ANEXO 3 - RESULTADOS DOS MODELOS ESTIMADOS SEGUNDO O PRO- CEDIMENTO 3}

\section{TABELA IV - COEFICIENTES ESTIMADOS PARA O MODELO DE UTILI- ZAÇÃO DE CONSULTAS MÉDICAS E INTERNAÇÃO - PLANO PÚBLICO}

\begin{tabular}{|c|c|c|c|c|c|c|c|c|}
\hline & \multicolumn{4}{|c|}{ CONSULTAS MÉDICAS } & \multicolumn{4}{|c|}{ Dias de internação } \\
\hline & \multicolumn{2}{|c|}{1998} & \multicolumn{2}{|c|}{2003} & \multicolumn{2}{|c|}{1998} & \multicolumn{2}{|c|}{2003} \\
\hline & $\begin{array}{l}\text { Indivíduos } \\
\text { com plano }\end{array}$ & $\begin{array}{l}\text { Indivíduos } \\
\text { sem plano }\end{array}$ & $\begin{array}{l}\text { Indivíduos } \\
\text { com plano }\end{array}$ & $\begin{array}{l}\text { Indivíduos } \\
\text { sem plano }\end{array}$ & $\begin{array}{l}\text { Indivíduos } \\
\text { com plano }\end{array}$ & $\begin{array}{l}\text { Indivíduos } \\
\text { sem plano }\end{array}$ & $\begin{array}{l}\text { Indivíduos } \\
\text { com plano }\end{array}$ & $\begin{array}{l}\text { Indivíduos } \\
\text { sem plano }\end{array}$ \\
\hline Até 18 anos & $-0.620^{\star * \star}$ & $-0.589^{* * *}$ & $-0.347^{\star * *}$ & $-0.704^{\star * *}$ & 0.005 & $-1.062^{\star \star *}$ & $-1.128^{* *}$ & $-1.697^{\star \star *}$ \\
\hline 18 a 29 anos & $-0.924^{\star \star *}$ & $-0.970^{\star \star \star}$ & $-0.672^{\star \star *}$ & $-0.995^{\star * *}$ & -0.160 & $-0.835^{\star \star \star}$ & $-1.144^{\star \star}$ & $-1.469^{\star \star *}$ \\
\hline 30 a 39 anos & $-0.797^{\star \star \star}$ & $-0.877^{\star \star \star}$ & $-0.566^{\star * *}$ & $-0.829^{\star \star *}$ & 0.117 & $-0.664^{\star *}$ & -0.447 & $-0.817^{\star \star *}$ \\
\hline 40 a 49 anos & $-0.790^{\star * *}$ & $-0.793^{\star \star \star}$ & $-0.572^{\star \star \star}$ & $-0.868^{\star * *}$ & -0.004 & $-0.808^{\star \star \star}$ & $-0.877^{*}$ & $-1.136^{\star \star *}$ \\
\hline 50 a 59 anos & $-0.744^{\star \star *}$ & $-0.732^{\star \star \star}$ & $-0.540^{\star * *}$ & $-0.752^{* * *}$ & -0.113 & $-0.700^{* *}$ & -0.559 & $-1.340^{\star \star *}$ \\
\hline 60 a 69 anos & $-0.678^{* * *}$ & $-0.601^{\star * *}$ & $-0.475^{\star \star \star}$ & $-0.677^{\star \star *}$ & 0.154 & -0.393 & $-0.826^{*}$ & $-1.067^{\star \star \star}$ \\
\hline +de 70 anos & $-0.573^{\star * *}$ & $-0.559^{* * *}$ & $-0.368^{* * *}$ & $-0.612^{\star \star *}$ & $1.171^{\star \star \star}$ & -0.222 & -0.299 & -0.689 \\
\hline $\begin{array}{l}\text { Presença de criança } \\
\text { na família }\end{array}$ & $0.095^{\star * *}$ & $0.182^{\star \star \star}$ & 0.012 & 0.070 & $0.290^{* *}$ & $0.311^{* *}$ & 0.196 & -0.187 \\
\hline $\begin{array}{l}\text { Presença de idoso } \\
\text { na família }\end{array}$ & 0.063 & $0.132^{\star *}$ & $0.087^{* *}$ & 0.076 & -0.218 & $0.679^{* * *}$ & $0.469^{* *}$ & -0.079 \\
\hline $\begin{array}{l}\text { Presença de mulher } \\
\text { em idade fértil na } \\
\text { família }\end{array}$ & 0.047 & $0.111^{\star *}$ & $0.078^{* *}$ & $0.146^{* * *}$ & -0.227 & 0.125 & $-0.325^{\star}$ & 0.124 \\
\hline Rondônia & $-0.190^{*}$ & $-0.305^{\star}$ & $-0.158^{*}$ & $-0.471^{* * *}$ & 0.099 & 0.455 & $0.597^{\star *}$ & 0.294 \\
\hline Acre & -0.086 & 0.264 & -0.061 & $-0.298^{\star}$ & $-2.305^{\star \star \star}$ & $2.458^{\star * *}$ & -0.498 & -0.067 \\
\hline Amazonas & -0.073 & $-0.375^{\star * \star}$ & -0.045 & 0.149 & -0.639 & -0.520 & -0.461 & 0.020 \\
\hline Roraima & 0.053 & $0.606^{\star \star *}$ & -0.131 & 0.123 & -1.138 & -0.526 & -0.589 & 0.279 \\
\hline Pará & $-0.190^{* \star *}$ & -0.057 & $-0.214^{\star \star *}$ & $-0.233^{* * *}$ & -0.456 & -0.023 & -0.231 & 0.218 \\
\hline Amapá & -0.118 & 0.092 & -0.240 & -0.083 & $-1.545^{\star \star \star}$ & $1.349^{*}$ & -0.008 & 1.133 \\
\hline Tocantins & $-0.224^{\star *}$ & -0.129 & $-0.485^{\star * *}$ & $-0.256^{\star \star *}$ & -0.473 & 0.095 & -0.170 & $0.974^{\star *}$ \\
\hline Maranhão & -0.008 & 0.035 & -0.065 & $-0.345^{\star \star *}$ & $-1.196^{\star \star \star}$ & -0.160 & 0.182 & $0.667^{*}$ \\
\hline Piauí & 0.102 & $-0.223^{\star \star}$ & 0.045 & 0.043 & -0.501 & 0.168 & -0.034 & -0.006 \\
\hline Ceará & -0.041 & $0.215^{\star}$ & $-0.259^{\star \star *}$ & $-0.265^{\star \star \star}$ & $-1.193^{\star \star \star}$ & 0.563 & $-0.780^{\star \star \star}$ & -0.416 \\
\hline Rio Grande do Norte & $0.429^{\star * \star}$ & 0.215 & $0.205^{*}$ & 0.306 & $-1.453^{\star * *}$ & 0.730 & 0.516 & 0.893 \\
\hline Paraíba & 0.094 & 0.186 & 0.154 & -0.006 & -0.434 & -0.031 & 0.101 & 0.427 \\
\hline Pernambuco & -0.034 & $0.211^{\star \star \star}$ & 0.024 & -0.044 & $-0.574^{*}$ & $0.544^{*}$ & -0.099 & 0.060 \\
\hline Alagoas & -0.039 & 0.171 & -0.131 & -0.099 & -0.672 & 0.002 & -0.311 & $-1.071^{*}$ \\
\hline Sergipe & $0.201^{* *}$ & 0.125 & 0.031 & 0.136 & -0.307 & 0.290 & $-1.634^{\star *}$ & $-0.714^{*}$ \\
\hline Bahia & 0.049 & 0.002 & -0.002 & -0.034 & $-0.960^{\star * \star}$ & 0.380 & -0.225 & 0.137 \\
\hline Minas Gerais & 0.005 & 0.069 & -0.076 & $-0.105^{*}$ & $-0.567^{*}$ & $0.567^{\star * *}$ & -0.278 & 0.500 \\
\hline Espírito Santo & $0.459^{\star * *}$ & 0.144 & $0.248^{* *}$ & 0.088 & $-0.780^{\star *}$ & -0.037 & 0.123 & -0.039 \\
\hline Rio de Janeiro & -0.027 & 0.090 & -0.050 & $-0.121^{\star *}$ & $-0.730^{* *}$ & 0.077 & -0.394 & 0.318 \\
\hline
\end{tabular}




\begin{tabular}{|c|c|c|c|c|c|c|c|c|}
\hline & \multicolumn{4}{|c|}{ CONSULTAS MÉDICAS } & \multicolumn{4}{|c|}{ Dias de internação } \\
\hline & \multicolumn{2}{|c|}{1998} & \multicolumn{2}{|c|}{2003} & \multicolumn{2}{|c|}{1998} & \multicolumn{2}{|c|}{2003} \\
\hline & $\begin{array}{l}\text { Indivíduos } \\
\text { com plano }\end{array}$ & $\begin{array}{l}\text { Indivíduos } \\
\text { sem plano }\end{array}$ & $\begin{array}{l}\text { Indivíduos } \\
\text { com plano }\end{array}$ & $\begin{array}{l}\text { Indivíduos } \\
\text { sem plano }\end{array}$ & $\begin{array}{l}\text { Indivíduos } \\
\text { com plano }\end{array}$ & $\begin{array}{l}\text { Indivíduos } \\
\text { sem plano }\end{array}$ & $\begin{array}{l}\text { Indivíduos } \\
\text { com plano }\end{array}$ & $\begin{array}{l}\text { Indivíduos } \\
\text { sem plano }\end{array}$ \\
\hline Paraná & 0.052 & 0.123 & $-0.172^{\star \star \star}$ & -0.097 & -0.420 & 0.282 & -0.128 & $-0.559^{\star *}$ \\
\hline Santa Catarina & $-0.136^{*}$ & $-0.174^{*}$ & -0.071 & $-0.219^{\star *}$ & 0.004 & -0.200 & -0.449 & -0.441 \\
\hline Rio Grande do Sul & $0.100^{* *}$ & 0.073 & 0.013 & $-0.105^{\star}$ & 0.004 & $0.349^{*}$ & 0.058 & 0.275 \\
\hline Mato Grosso do Sul & 0.052 & 0.220 & -0.057 & -0.002 & 0.039 & $0.687^{*}$ & -0.387 & 0.192 \\
\hline Mato Grosso & $-0.251^{*}$ & -0.113 & $-0.384^{\star \star \star}$ & -0.133 & 0.384 & -0.241 & -0.734 & 0.328 \\
\hline Goiás & -0.077 & -0.045 & $-0.124^{\star *}$ & $-0.138^{\star *}$ & -0.025 & 0.287 & 0.281 & $0.639^{\star * *}$ \\
\hline Distrito Federal & $0.118^{\star *}$ & 0.024 & $-0.130^{\star *}$ & -0.077 & -0.511 & 0.161 & $-0.573^{* *}$ & -0.134 \\
\hline Região metrop. & $0.247^{\star \star *}$ & $0.251^{\star \star *}$ & $0.308^{\star \star *}$ & $0.366^{\star \star \star}$ & 0.153 & -0.371 & 0.425 & $0.858^{\star \star *}$ \\
\hline Região urbana & -0.011 & $0.114^{*}$ & 0.111 & $0.140^{*}$ & -0.235 & -0.183 & 0.310 & $0.626^{* * *}$ \\
\hline $\begin{array}{l}\text { Número de } \\
\text { componentes na } \\
\text { família }\end{array}$ & $-0.053^{* \star \star}$ & $-0.072^{\star \star \star}$ & $-0.035^{\star * *}$ & $-0.045^{\star \star \star}$ & -0.024 & $-0.066^{*}$ & -0.001 & -0.017 \\
\hline Coluna & $0.183^{* * *}$ & $0.160^{\star \star \star}$ & $0.187^{\star \star *}$ & $0.178^{\star \star \star}$ & -0.080 & -0.153 & 0.233 & $-0.319^{* *}$ \\
\hline Artrite & 0.048 & 0.085 & 0.044 & $0.103^{\star \star}$ & $-0.408^{* * *}$ & $-0.326^{\star}$ & -0.082 & -0.065 \\
\hline Câncer & $0.522^{* * *}$ & $0.557^{\star \star \star}$ & $0.519^{\star \star \star}$ & $0.449^{\star \star *}$ & $2.080^{\star \star *}$ & $2.196^{\star \star *}$ & $0.587^{\star *}$ & $1.075^{\star \star *}$ \\
\hline Diabetes & $0.390^{* \star *}$ & $0.344^{\star \star \star}$ & $0.245^{\star \star \star}$ & $0.358^{\star * \star}$ & 0.001 & $0.920^{* * *}$ & 0.338 & $1.202^{* * *}$ \\
\hline Asma & $0.362^{* * *}$ & $0.496^{* \star *}$ & $0.241^{\star * *}$ & $0.238^{\star \star \star}$ & $0.651^{* * *}$ & 0.279 & $0.687^{\star \star \star}$ & $1.039^{* * *}$ \\
\hline Hipertensão & $0.268^{* * *}$ & $0.340^{* \star *}$ & $0.220^{* \star *}$ & $0.259^{* * *}$ & $0.447^{\star \star \star}$ & 0.156 & 0.032 & $-0.412^{* * *}$ \\
\hline Coração & $0.204^{* * *}$ & $0.406^{* \star *}$ & $0.168^{* * *}$ & $0.217^{\star \star \star}$ & $0.800^{* \star *}$ & $0.643^{\star * *}$ & $0.465^{* \star *}$ & $0.927^{\star * *}$ \\
\hline Renal & $0.185^{\star \star \star}$ & 0.054 & $0.276^{\star \star}$ & $0.138^{\star}$ & $0.504^{\star \star \star}$ & $0.842^{\star \star \star}$ & $1.016^{\star \star \star}$ & $0.783^{\star \star}$ \\
\hline Depressão & $0.182^{\star \star \star}$ & $0.258^{* \star \star}$ & $0.305^{\star \star \star}$ & $0.320^{\star \star \star}$ & $0.543^{\star \star *}$ & $0.549^{\star \star \star}$ & $0.568^{\star \star \star}$ & $0.855^{\star \star \star}$ \\
\hline Tuberculose & 0.182 & 0.131 & -0.009 & 0.012 & $1.819^{* \star *}$ & 0.875 & -0.224 & 1.028 \\
\hline Tendinite & $0.244^{* * *}$ & $0.168^{\star *}$ & $0.250^{* \star *}$ & 0.058 & 0.200 & 0.493 & $-0.495^{\star \star *}$ & $-1.226^{* * *}$ \\
\hline Cirrose & $0.340^{*}$ & $0.534^{\star \star}$ & 0.092 & $0.586^{\star}$ & $1.256^{\star \star}$ & -0.255 & $0.921^{\star *}$ & $2.347^{\star \star \star}$ \\
\hline Saúde autoavaliada & $-0.468^{* \star \star}$ & $-0.568^{\star \star \star}$ & $-0.373^{* \star \star}$ & $-0.552^{\star \star \star}$ & $-1.218^{\star \star \star}$ & $-1.476^{\star \star *}$ & $-1.141^{\star * *}$ & $-1.715^{\star * *}$ \\
\hline Idade do chefe & $-0.007^{\star \star \star}$ & $-0.007^{\star \star \star}$ & $-0.006^{\star \star \star}$ & $-0.005^{\star \star \star}$ & $-0.018^{\star \star \star}$ & $-0.018^{\star \star \star}$ & $-0.015^{\star \star}$ & -0.007 \\
\hline Sexo & $-0.312^{* \star \star}$ & $-0.339^{\star \star \star}$ & $-0.285^{* * *}$ & $-0.285^{\star \star \star}$ & -0.125 & -0.162 & 0.023 & 0.096 \\
\hline Até 3 anos est. & $-0.299^{\star \star \star}$ & -0.074 & $-0.143^{\star \star \star}$ & -0.078 & 0.154 & $0.431^{\star \star}$ & 0.266 & $0.413^{\star \star}$ \\
\hline De 4 a 7 anos est. & $-0.199^{\star \star \star}$ & 0.031 & $-0.112^{\star \star \star}$ & -0.057 & 0.200 & $0.558^{\star \star \star}$ & 0.187 & $0.627^{\star \star \star}$ \\
\hline De 8 a 10 anos est. & $-0.120^{\star \star \star}$ & 0.124 & -0.051 & -0.087 & 0.308 & $0.450^{\star *}$ & -0.120 & $0.411^{\star *}$ \\
\hline De 11 a 14 anos est. & $-0.059^{*}$ & 0.031 & $-0.058^{\star}$ & 0.012 & 0.037 & -0.082 & 0.140 & $0.723^{* \star *}$ \\
\hline Qualidade & $0.384^{\star * *}$ & $0.504^{\star \star \star}$ & $0.370^{\star \star \star}$ & $0.439^{\star \star \star}$ & $0.315^{\star \star \star}$ & $0.723^{\star \star \star}$ & $0.498^{\star \star *}$ & $0.463^{\star \star *}$ \\
\hline Acesso & $0.172^{\star \star \star}$ & 0.137 & $0.232^{\star \star}$ & 0.039 & 0.229 & 0.506 & 0.373 & 0.289 \\
\hline Constante & $2.289^{\star * *}$ & $1.716^{\star \star \star}$ & $1.981^{\star * *}$ & $1.924^{\star * *}$ & $0.937^{\star}$ & 0.315 & 0.715 & -0.253 \\
\hline
\end{tabular}

Nota: ${ }^{*}$ significativo a $10 \% ;{ }^{*}$ significativo a $5 \% ;{ }^{* *}$ significativo a $1 \%$. 


\section{ANEXO 4 - TESTES DAS MÉDIAS DAS COVARIADAS ANTES E DEPOIS DO MATCHING}

\section{TABELA V - MÉDIAS DAS COVARIADAS SEGUNDO OS GRUPOS DE COM- PARAÇÃO E TRATAMENTO (TODOS OS PLANOS) - 1998}

\begin{tabular}{|c|c|c|c|c|}
\hline \multirow[t]{2}{*}{ Covariadas } & \multicolumn{2}{|c|}{ Antes do Pareamento } & \multicolumn{2}{|c|}{ Após o pareamento } \\
\hline & Sem plano & $\begin{array}{c}\text { Com plano } \\
\text { (tratamento) }\end{array}$ & Sem plano & $\begin{array}{l}\text { Com plano } \\
\text { (tratamento) }\end{array}$ \\
\hline Até 18 anos & 0,3864 & $0,3131^{* \star *}$ & 0,3140 & $0,3131-$ \\
\hline 18 a 29 anos & 0,2102 & $0,1874^{\star \star \star}$ & 0,1899 & 0,1874- \\
\hline 30 a 39 anos & 0,1404 & $0,1736^{\star \star \star}$ & 0,1722 & $0,1736-$ \\
\hline 40 a 49 anos & 0,1069 & $0,1426^{\star \star *}$ & 0,1416 & $0,1426-$ \\
\hline 50 a 59 anos & 0,0709 & $0,0878^{\star \star \star}$ & 0,0873 & $0,0878-$ \\
\hline 60 a 69 anos & 0,0478 & $0,0569^{* \star *}$ & 0,0565 & $0,0569-$ \\
\hline +de 70 anos & 0,0371 & $0,0382-$ & 0,0381 & $0,0382-$ \\
\hline Criança na família & 0,5894 & $0,4815^{\star \star \star}$ & 0,4699 & $0,4815^{\star \star *}$ \\
\hline Idoso na família & 0,1410 & $0,1325^{\star \star \star}$ & 0,1260 & $0,1325^{\star * *}$ \\
\hline Mulher em idade fértil na família & 0,8412 & $0,8544^{\star \star \star}$ & 0,8553 & $0,8544-$ \\
\hline $1^{\circ}$. Dec de rfpc & 0,1317 & $0,0101^{* \star *}$ & 0,0125 & $0,0101^{\star \star *}$ \\
\hline $2^{\circ}$. Dec de rfpc & 0,1249 & $0,0123^{\star \star \star}$ & 0,0152 & $0,0123^{\star * *}$ \\
\hline $3^{\circ}$. Dec de rfpc & 0,1205 & $0,0225^{\star \star \star}$ & 0,0241 & $0,0225^{\star *}$ \\
\hline $4^{\circ}$. Dec de rfpc & 0,1155 & $0,0355^{\star \star \star}$ & 0,0362 & $0,0355-$ \\
\hline 5․ Dec de rfpc & 0,1178 & $0,0597^{\star \star \star}$ & 0,0610 & $0,0597-$ \\
\hline 6‥ Dec de rfpc & 0,1065 & $0,0738^{\star \star \star}$ & 0,0747 & $0,0738-$ \\
\hline $7^{\circ}$. Dec de rfpc & 0,0924 & $0,1059^{\star \star \star}$ & 0,1063 & $0,1059-$ \\
\hline $8^{\circ}$. Dec de rfpc & 0,0885 & $0,1544^{\star \star *}$ & 0,1550 & $0,1544-$ \\
\hline 9․ Dec de rfpc & 0,0671 & $0,2200^{* \star *}$ & 0,2221 & $0,2200-$ \\
\hline 10․ Dec de rfpc & 0,0346 & $0,3053^{* \star \star}$ & 0,2924 & $0,3053^{\star \star \star}$ \\
\hline Chefe com carteira & 0,2021 & $0,3850^{\star * \star}$ & 0,3803 & $0,3850^{* *}$ \\
\hline Chefe sem carteira & 0,1550 & $0,0556^{\star \star \star}$ & 0,0550 & $0,0556-$ \\
\hline Chefe Doméstico & 0,0345 & $0,0085^{\star \star \star}$ & 0,0085 & $0,0085-$ \\
\hline Chefe Conta Própria & 0,3046 & $0,1334^{\star \star *}$ & 0,1390 & $0,1334^{\star \star \star}$ \\
\hline Chefe Empregador & 0,0373 & $0,0838^{* \star \star}$ & 0,0837 & $0,0838-$ \\
\hline Chefe Não Remunerado & 0,0239 & $0,0095^{\star \star \star}$ & 0,0095 & $0,0095-$ \\
\hline Chefe - Não PEA & 0,1744 & $0,1708-$ & 0,1721 & $0,1708-$ \\
\hline Chefe Desocupado & 0,0431 & $0,0227^{\star \star \star}$ & 0,0226 & $0,0227-$ \\
\hline Chefe Militar/Func. Público & 0,0246 & $0,1304^{\star \star \star}$ & 0,1289 & $0,1304-$ \\
\hline Sexo & 0,4993 & $0,4631^{\star \star \star}$ & 0,4652 & $0,4631-$ \\
\hline Região metrop./ urbana & 0,7465 & $0,9509^{\star \star \star}$ & 0,9540 & $0,9509^{* \star \star}$ \\
\hline
\end{tabular}


TABELA VI - MÉDIAS DAS COVARIADAS SEGUNDO OS GRUPOS DE COMPARAÇÃO E TRATAMENTO (TODOS OS PLANOS) - 2003

\begin{tabular}{|c|c|c|c|c|c|}
\hline & \multicolumn{2}{|c|}{ Antes do Pareamento } & \multicolumn{3}{|c|}{ Depois do Pareamento } \\
\hline & Sem plano & Com plano & Sem plano & Com plano & \\
\hline Até 18 anos & 0,3548 & $0,2703^{\star \star \star}$ & 0,2712 & 0,2703 & - \\
\hline 18 a 29 anos & 0,2197 & $0,2003^{\star \star *}$ & 0,2019 & 0,2003 & - \\
\hline 30 a 39 anos & 0,1430 & $0,1642^{\star \star *}$ & 0,1630 & 0,1642 & - \\
\hline 40 a 49 anos & 0,1155 & $0,1488^{\star \star *}$ & 0,1483 & 0,1488 & - \\
\hline 50 a 59 anos & 0,0773 & $0,1026^{* * *}$ & 0,1022 & 0,1026 & - \\
\hline 60 a 69 anos & 0,0500 & $0,0618^{\star * *}$ & 0,0615 & 0,0618 & - \\
\hline +de 70 anos & 0,0395 & $0,0516^{\star \star *}$ & 0,0516 & 0,0516 & - \\
\hline Criança na família & 0,5458 & $0,4217^{\star \star \star}$ & 0,4081 & 0,4217 & *** \\
\hline Idoso na família & 0,1399 & $0,1510^{* \star *}$ & 0,1451 & 0,1510 & *** \\
\hline Mulher em idade fértil na família & 0,8265 & $0,8237^{\star}$ & 0,8245 & 0,8237 & - \\
\hline 1․ Dec de rfpc & 0,1229 & $0,0107^{\star * *}$ & 0,0130 & 0,0107 & *** \\
\hline $2^{\circ}$. Dec de rfpc & 0,1218 & $0,0102^{\star \star *}$ & 0,0122 & 0,0102 & *** \\
\hline 3․ Dec de rfpc & 0,1187 & $0,0207^{\star \star \star}$ & 0,0218 & 0,0207 & * \\
\hline 4․ Dec de rfpc & 0,1156 & $0,0345^{\star \star *}$ & 0,0355 & 0,0345 & - \\
\hline 5․ Dec de rfpc & 0,1118 & $0,0506^{* \star *}$ & 0,0513 & 0,0506 & - \\
\hline 6․ Dec de rfpc & 0,1326 & $0,0896^{* * *}$ & 0,0928 & 0,0896 & *** \\
\hline $7^{\circ}$. Dec de rfpc & 0,0794 & $0,0892^{\star \star *}$ & 0,0892 & 0,0892 & - \\
\hline 8․ Dec de rfpc & 0,0907 & $0,1521^{\star \star *}$ & 0,1530 & 0,1521 & - \\
\hline 9․ Dec de rfpc & 0,0715 & $0,2241^{* * *}$ & 0,2244 & 0,2241 & - \\
\hline 10․ Dec de rfpc & 0,0345 & $0,3178^{* * *}$ & 0,3063 & 0,3178 & *** \\
\hline Chefe com carteira & 0,2062 & $0,3680^{\star \star *}$ & 0,3637 & 0,3680 & * \\
\hline Chefe sem carteira & 0,1481 & $0,0594^{\star \star *}$ & 0,0586 & 0,0594 & - \\
\hline Chefe Doméstico & 0,0425 & $0,0106^{* * *}$ & 0,105 & 0,0106 & - \\
\hline Chefe Conta Própria & 0,2743 & $0,1344^{* * *}$ & 0,1390 & 0,1344 & $* * *$ \\
\hline Chefe Empregador & 0,0345 & $0,0876^{* \star *}$ & 0,0875 & 0,0876 & - \\
\hline Chefe Não Remunerado & 0,0276 & $0,0123^{\star * *}$ & 0,0122 & 0,0123 & - \\
\hline Chefe - Não PEA & 0,1860 & $0,1823^{\star \star}$ & 0,1838 & 0,1823 & - \\
\hline Chefe Desocupado & 0,0535 & $0,0223^{\star \star *}$ & 0,0222 & 0,0223 & - \\
\hline Chefe Militar/Func. Público & 0,0269 & $0,01228^{* * *}$ & 0,1222 & 0,01228 & - \\
\hline Sexo & 0,4973 & $0,4597^{\star \star \star}$ & 0,4588 & 0,4597 & - \\
\hline Região metrop./ urbana & 0,8053 & $0,9611^{\star \star \star}$ & 0,9639 & 0,9611 & $* \star *$ \\
\hline
\end{tabular}


TABELA VII - MÉDIAS DAS COVARIADAS SEGUNDO OS GRUPOS DE COMPARAÇÃO E TRATAMENTO (PIASP) - 1998

\begin{tabular}{|c|c|c|c|c|}
\hline & \multicolumn{2}{|c|}{ Antes do Pareamento } & \multicolumn{2}{|c|}{ Após o Pareamento } \\
\hline & Sem plano & Com plano & Sem plano & Com plano \\
\hline Até 18 anos & 0,3864 & $0,3333^{\star \star *}$ & 0,3363 & 0,3333- \\
\hline 18 a 29 anos & 0,2102 & $0,1657^{\star \star *}$ & 0,1717 & $0,1657^{\star *}$ \\
\hline 30 a 39 anos & 0,1404 & $0,1575^{\star \star \star}$ & 0,1583 & $0,1575-$ \\
\hline 40 a 49 anos & 0,1069 & $0,1492^{\star * *}$ & 0,1468 & $0,1492-$ \\
\hline 50 a 59 anos & 0,0709 & $0,0942^{* \star *}$ & 0,0926 & $0,0942-$ \\
\hline 60 a 69 anos & 0,0478 & $0,0594^{* * *}$ & 0,0582 & 0,0594- \\
\hline +de 70 anos & 0,0371 & $0,0403^{\star \star}$ & 0,0402 & $0,0403-$ \\
\hline Criança na família & 0,5844 & $0,4792^{\star \star *}$ & 0,4668 & $0,4792^{* \star *}$ \\
\hline Idoso na família & 0,1410 & $0,1408-$ & 0,1308 & $0,1408^{* * *}$ \\
\hline Mulher em idade fértil na família & 0,8412 & $0,8459^{*}$ & 0,8481 & $0,8459-$ \\
\hline $1^{\circ}$. Dec de rfpc & 0,1317 & $0,0105^{* * *}$ & 0,0147 & $0,0105^{\star * *}$ \\
\hline $2^{\circ}$. Dec de rfpc & 0,1249 & $0,0214^{\star \star \star}$ & 0,0255 & $0,0214^{* * *}$ \\
\hline 3o. Dec de rfpc & 0,1205 & $0,0302^{\star \star *}$ & 0,0320 & $0,0302-$ \\
\hline $4^{\circ}$. Dec de rfpc & 0,1155 & $0,0457^{\star \star *}$ & 0,0473 & $0,0457-$ \\
\hline $5^{\circ}$. Dec de rfpc & 0,1178 & $0,0629^{\star \star *}$ & 0,0639 & 0,0629 \\
\hline 60. Dec de rfpc & 0,1065 & $0,0768^{\star \star \star}$ & 0,0778 & $0,0768-$ \\
\hline $7^{\circ}$. Dec de rfpc & 0,0924 & $0,1105^{\star \star *}$ & 0,1116 & $0,1105-$ \\
\hline $8^{\circ}$. Dec de rfpc & 0,0885 & $0,1622^{\star \star \star}$ & 0,1629 & $0,1622-$ \\
\hline 9o. Dec de rfpc & 0,0671 & $0,2148^{\star \star *}$ & 0,2141 & $0,2148-$ \\
\hline 10․ Dec de rfpc & 0,0346 & $0,2646^{\star \star *}$ & 0,2497 & $0,2646^{\star \star *}$ \\
\hline Chefe com carteira & 0,2021 & $0,1986-$ & 0,1964 & $0,1986-$ \\
\hline Chefe sem carteira & 0,1550 & $0,0623^{\star \star *}$ & 0,0619 & $0,0623-$ \\
\hline Chefe Doméstico & 0,0345 & $0,0051^{\star \star *}$ & 0,0051 & $0,0051-$ \\
\hline Chefe Conta Própria & 0,3046 & $0,1174^{\star \star *}$ & 0,1244 & $0,1174^{\star \star *}$ \\
\hline Chefe Empregador & 0,0373 & $0,0386-$ & 0,0384 & $0,0386-$ \\
\hline Chefe Não Remunerado & 0,0239 & $0,0109^{\star \star *}$ & 0,0110 & $0,0109-$ \\
\hline Chefe - Não PEA & 0,1744 & $0,2003^{\star \star *}$ & 0,2012 & $0,2003-$ \\
\hline Chefe Desocupado & 0,0431 & $0,0222^{\star \star *}$ & 0,0218 & 0,0222- \\
\hline Chefe Militar/Func. Público & 0,0246 & $0,3196^{\star \star \star}$ & 0,3393 & $0,3196-$ \\
\hline Sexo & 0,4993 & $0,4556^{* \star *}$ & 0,4594 & $0,4556-$ \\
\hline Região metrop./ urbana & 0,7465 & $0,9480^{\star \star \star}$ & 0,9551 & $0,9480^{\star \star \star}$ \\
\hline
\end{tabular}


TABELA VII - MÉDIAS DAS COVARIADAS SEGUNDO OS GRUPOS DE COMPARAÇÃO E TRATAMENTO (PIASP) - 2003

\begin{tabular}{|c|c|c|c|c|}
\hline & \multicolumn{2}{|c|}{ Antes do Pareamento } & \multicolumn{2}{|c|}{ Após o Pareamento } \\
\hline & Sem plano & $\begin{array}{c}\text { Com plano } \\
\text { (tratamento) }\end{array}$ & Sem plano & $\begin{array}{c}\text { Com plano } \\
\text { (tratamento) }\end{array}$ \\
\hline Até 18 anos & 0,3548 & $0,2714^{* * *}$ & 0,2737 & $0,2714-$ \\
\hline 18 a 29 anos & 0,2197 & $0,1676^{\star \star *}$ & 0,1709 & $0,1676-$ \\
\hline 30 a 39 anos & 0,1430 & $0,1437-$ & 0,1416 & $0,1437-$ \\
\hline 40 a 49 anos & 0,1150 & $0,1652^{* \star *}$ & 0,1638 & $0,1652-$ \\
\hline 50 a 59 anos & 0,773 & $0,1236^{\star \star \star}$ & 0,1226 & $0,1236-$ \\
\hline 60 a 69 anos & 0,0500 & $0,0737^{\star \star \star}$ & 0,0729 & $0,0737-$ \\
\hline +de 70 anos & 0,0395 & $0,0544^{* \star *}$ & 0,0543 & $0,0544-$ \\
\hline Criança na família & 0,5458 & $0,3902^{* * *}$ & 0,3730 & $0,3902^{* \star *}$ \\
\hline Idoso na família & 0,1399 & $0,1658^{\star \star \star}$ & 0,1573 & $0,1658^{* \star \star}$ \\
\hline Mulher em idade fértil na família & 0,8265 & $0,8013^{* \star *}$ & 0,8042 & 0,8013- \\
\hline 1‥ Dec de rfpc & 0,1229 & $0,0085^{* * *}$ & 0,0118 & $0,0085^{* \star *}$ \\
\hline $2^{\circ}$. Dec de rfpc & 0,1218 & $0,0082^{* \star *}$ & 0,0108 & $0,0082^{\star \star \star}$ \\
\hline $3^{\circ}$. Dec de rfpc & 0,1187 & $0,0191^{\star \star *}$ & 0,0211 & $0,0191^{*}$ \\
\hline 4․․ Dec de rfpc & 0,1156 & $0,0265^{* \star *}$ & 0,0284 & $0,0265-$ \\
\hline $5^{\circ}$. Dec de rfpc & 0,1118 & $0,0459^{\star \star \star}$ & 0,0475 & $0,0459-$ \\
\hline 6․ Dec de rfpc & 0,1326 & $0,0924^{* \star *}$ & 0,0976 & $0,0924^{* *}$ \\
\hline $7^{\circ}$. Dec de rfpc & 0,0794 & $0,0938^{* \star *}$ & 0,0935 & $0,0938-$ \\
\hline $8^{\circ}$. Dec de rfpc & 0,0907 & $0,1621^{* * *}$ & 0,1640 & $0,1621-$ \\
\hline 9․ Dec de rfpc & 0,0715 & $0,2453^{\star \star *}$ & 0,2442 & $0,2453-$ \\
\hline $10^{\circ}$. Dec de rfpc & 0,0345 & $0,2977^{\star \star *}$ & 0,2806 & $0,2977^{* * *}$ \\
\hline Chefe com carteira & 0,2062 & $0,1656^{\star \star \star}$ & 0,1633 & $0,1656-$ \\
\hline Chefe sem carteira & 0,1481 & $0,0608^{* \star *}$ & 0,0597 & $0,0608-$ \\
\hline Chefe Doméstico & 0,0425 & $0,0069^{* \star *}$ & 0,0069 & 0,0069 \\
\hline Chefe Conta Própria & 0,2743 & $0,1092^{\star \star *}$ & 0,1139 & $0,1092^{*}$ \\
\hline Chefe Empregador & 0,0345 & $0,0478^{\star \star *}$ & 0,0478 & $0,0478-$ \\
\hline Chefe Não Remunerado & 0,0276 & $0,0146^{\star \star \star}$ & 0,0142 & 0,0146- \\
\hline Chefe - Não PEA & 0,1860 & $0,2143^{\star \star *}$ & 0,2150 & $0,2143-$ \\
\hline Chefe Desocupado & 0,0535 & $0,0226^{\star * *}$ & 0,0222 & 0,0226- \\
\hline Chefe Militar/Func. Público & 0,2693 & $0,3578^{\star \star *}$ & 0,3565 & $0,3578-$ \\
\hline Sexo & 0,8053 & $0,9691^{\star \star *}$ & 0,9733 & $0,9691^{* * *}$ \\
\hline Região metrop./ urbana & 0,4973 & $0,4487^{* \star *}$ & 0,4432 & $0,4487-$ \\
\hline
\end{tabular}

